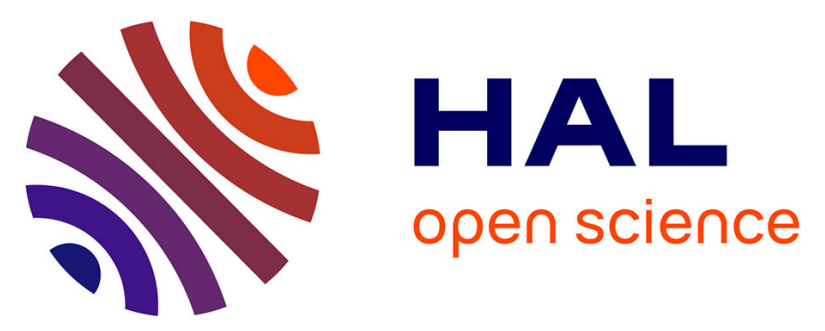

\title{
Photovoltaic properties of supramolecular assemblies obtained by incorporation of Preysler's type polyoxometalate in a polycationic copolymer of porphyrin
}

Zhaohui Huo, Antoine Bonnefont, Yiming Liang, Rana Farha, Michel Goldmann, Eric Saint-Aman, Hualong Xu, Christophe Bucher, Laurent Ruhlmann

\section{- To cite this version:}

Zhaohui Huo, Antoine Bonnefont, Yiming Liang, Rana Farha, Michel Goldmann, et al.. Photovoltaic properties of supramolecular assemblies obtained by incorporation of Preysler's type polyoxometalate in a polycationic copolymer of porphyrin. Electrochimica Acta, 2018, 274, pp.177 - 191. 10.1016/j.electacta.2018.04.088 . hal-01787526

\section{HAL Id: hal-01787526 \\ https: / hal.sorbonne-universite.fr/hal-01787526}

Submitted on 7 May 2018

HAL is a multi-disciplinary open access archive for the deposit and dissemination of scientific research documents, whether they are published or not. The documents may come from teaching and research institutions in France or abroad, or from public or private research centers.
L'archive ouverte pluridisciplinaire HAL, est destinée au dépôt et à la diffusion de documents scientifiques de niveau recherche, publiés ou non, émanant des établissements d'enseignement et de recherche français ou étrangers, des laboratoires publics ou privés. 


\section{Photovoltaic properties of supramolecular assemblies obtained by incorporation of Preysler's type polyoxometalate in a polycationic copolymer of porphyrin}

\section{Zhaohui Huo, ${ }^{\text {a }}$ Antoine Bonnefont, ${ }^{a}$ Rana Farha, ${ }^{\text {b,c }}$ Michel Goldmann, ${ }^{\text {,dd }}$ Eric Saint-Aman, ${ }^{\mathrm{e}}$ Hualong Xu, ${ }^{\mathrm{f}}$ Christophe Bucher, ${ }^{\mathrm{g}}$ and Laurent Ruhlmann ${ }^{\mathrm{a} *}$}

${ }^{a}$ Université de Strasbourg, Institut de Chimie, UMR CNRS 7177, 4 rue Blaise Pascal, CS 90032, 67081 Strasbourg cedex, France,

${ }^{\mathrm{b}}$ Institut des NanoSciences de Paris, UMR CNRS 7588, Université Paris 6, 4 place Jussieu, boîte courrier 840, F - 75252 Paris, France,

${ }^{\mathrm{c}}$ Laboratoire d'Analyse et Contrôle des Systèmes Complexes - LACSC-ECE Paris Ecole d'Ingénieurs, 37 Quai de Grenelle, F - 75015 Paris, France,

${ }^{d}$ Université Paris Descartes, 45 rue des Saints Pères, F - 75006 Paris, France,

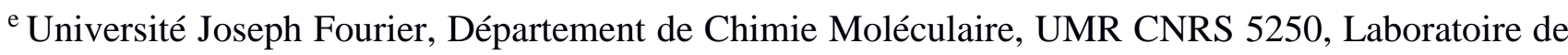
Chimie Inorganique Rédox, BP-53, 38041 Grenoble Cedex 9, France,

${ }^{\mathrm{f}}$ Department of Chemistry, Shanghai Key Laboratory of Molecular Catalysis and Innovative Materials and Laboratory of Advanced Materials, Fudan University, Shanghai 200433, People's Republic of China,

${ }^{\mathrm{g}}$ Ecole Normale Supérieure de Lyon - Université Lyon 1, Laboratoire de Chimie-UMR CNRS 5182 46 allée d'Italie - 69364 Lyon Cedex 07, France. 


\begin{abstract}
Poly-zinc-octaethylporphyrin/ $\mathrm{P}_{5} \mathrm{~W}_{30}$ films have been obtained through incorporation of Preyssler-type polyoxometalate ions, namely $\left[\mathrm{NaP}_{5} \mathrm{~W}_{30} \mathrm{O}_{110}\right]^{14-}\left(\mathbf{P}_{5} \mathbf{W}_{30}\right)$ into zinc octaethylporphyrin/viologen-based polymers (poly-ZnOEP) films. The latter has been achieved through a metathesis reaction involving exchange of the initial counter ions $\left(\mathrm{PF}_{6}^{-}\right)$of the positively charged poly-ZnOEP by $\mathbf{P}_{5} \mathbf{W}_{30}$. The investigated polymers involve ZnOEP units covalently linked through either dicationic monoviologen or through tetracationic bis-viologen spacers. These copolymers have been characterized by UV/Vis spectroscopy, X-ray photoelectron spectroscopy, electrochemistry, AFM and by electrochemical impedance spectroscopy. Formation of the polymers through electropolymerization of viologen and porphyrin building blocks was monitored by EQCM. QCM was also used to study the exchange of $\mathrm{PF}_{6}{ }^{-}$by $\left[\mathrm{NaP}_{5} \mathrm{~W}_{30} \mathrm{O}_{110}\right]^{14-}$. The photovoltaic performances under visible light irradiation have also been investigated by photocurrent transient measurements carried out under visible illumination.
\end{abstract}

\title{
1. Introduction
}

Polyoxometalates (POMs) are a structurally diverse family of anionic metal -oxygen cluster anions constituted of metal elements in their highest oxidation states finding applications in analytical chemistry, medicine, homogeneous and heterogeneous catalysis, electronic, and materials science. ${ }^{1}$ Owing to their robustness and large number of metallic centers, POMs can undergo multi-electron photoredox reversible processes without structural alteration. ${ }^{2}$ It is furthermore possible to use various type of structure (Lindqvist, Keggin, Dawson, Sandwich types...) and to change the type of heteroatom $\left(\mathrm{V}^{\mathrm{V}}, \mathrm{Nb}^{\mathrm{V}}, \mathrm{Mo}^{\mathrm{VI}}, \mathrm{W}^{\mathrm{VI}}, \ldots\right)$ involved in their structure to adjust the redox potentials. Preyssler-type POMs, $\mathrm{K}_{12.5} \mathrm{Na}_{1.5}\left[\mathrm{NaP}_{5} \mathrm{~W}_{30} \mathrm{O}_{110}\right]$, have already been incorporated in photochromic ${ }^{3}$ and thermochromic ${ }^{4}$ composite films showing good reversibility in the coloration/decoloration process and stability. Preyssler-type POMs are furthermore far less investigated than the most common Dawson, Lindqvist or Anderson structures, especially in the context of photovoltaic. 
The great heat stability and processability of POM-containing polymers make them indeed perfectly suited to the development of functional photovoltaic devices. Peng et al. have reported the first example of polymer featuring a conjugated photoactive organic skeleton ${ }^{5}$ and hexamolybdate type polyoxometalate (POM) clusters inserted into the main-chain or as side-chain pendant groups. ${ }^{6-7}$ These hybrid polymers exhibit intense visible absorption whose fluorescence is quenched by the integrated POMs. Such polymers have been used as key components within single-layer photovoltaic devices (indium tin oxide (ITO)/polymer/Ca configuration) featuring a power conversion efficiency (PCE) of $0.15 \% .{ }^{6 \mathbf{b}}$ More recently, Peng et al. have reported a different type of organic-inorganic hybrid conjugated copolymer exhibiting different loadings of hexamolybdate type POMs covalently embedded in the main chain with imide-functionalized naphthodithiophene and 3,30-didodecyloxy bithiophene units presenting PCEs up to $0.31 \% .^{7 \mathbf{b}}$ The photovoltaic performance of this two hybrid materials are already very encouraging even if further improvements are obviously needed for applications. Several other covalently-linked POM-polymer hybrids have been described but their photovoltaic properties have not been reported. ${ }^{8}$ The low photovoltaic efficiency reported in the articles mentioned above may be explained by the fact that POMs can be excited by light mainly under UV irradiations $(\mathrm{O} \rightarrow \mathrm{M}$ ligand-to-metal charge-transfer absorption band). This means that only a small fraction of the incoming light can be converted into electrical energy, which severely limits the applications of such materials for the construction of the photoelectric devices and may explain the small power conversion efficiency (PCE) reported by Peng et al. ${ }^{6-7}$

To address this issue, POMs can be associated via covalent, coordination or non-covalent bonding to porphyrin chromophore known to absorb visible light.9-11 The introduction of POM-porphyrin hybrids into polymeric and surface supported materials is indeed a very promising approach toward functional devices with efficient photocatalytic or photovoltaic properties.

In line with this strategy, we have previously reported a straightforward and efficient electropolymerization procedure leading to mixed porphyrin-POM copolymer films, involving either Anderson, Dawson or Linqvist ${ }^{\mathbf{1 2}}$ type of POMs, with remarkable photocatalytic properties under visible light illumination. 
A similar electropolymerization procedure was also implemented with dipyridyl ligands such as the 4,4'-bipyridine, but without polyoxometalate, to provide access to a series of cationic porphyrin- and viologen-based copolymers. In this case, the associated POM-porphyrin films could be prepared by exchanging the $\mathrm{PF}_{6}{ }^{-}$counter ions with Keggin type polyanion $\left[\mathrm{SiW}_{12} \mathrm{O}_{40}\right]^{4-}$. This doping process was found to induce drastic modifications of the morphology evidenced by AFM. ${ }^{13}$ Such porphyrin-POM electrostatic assemblies could potentially be involved in photoinduced electron transfers between the porphyrin antenna (donor of electron) to the viologen spacers as well as the POM (acceptors of electron). These materials are thus promising for the development of photoelectric devices where the type of POMs can be modulated easily. In the first example published, ${ }^{\mathbf{1 3}}$ only the fabrication of the electrostatic supramolecular structure was described, and the photocurrent generation as well as the photocatalytic behavior, under irradiation was not studied.

In the present paper, we have further exploited this strategy to incorporate a Preyssler-type POM $\left(\left[\mathrm{NaP}_{5} \mathrm{~W}_{30} \mathrm{O}_{110}\right]^{14-} ; \mathbf{P}_{5} \mathbf{W}_{30}\right)$ into two kinds of electropolymerized poly-ZnOEP films, involving either simple rigid viologen $\left(-\mathrm{py}^{+}-\mathrm{py}^{+}-\right)$or more flexible bis-viologen, $\left.-\mathrm{py}^{+}-\mathrm{py}^{+}-\left(\mathrm{CH}_{2}\right)_{3}-\mathrm{py}^{+}-\mathrm{py}^{+}-\right)$spacers introduced between the zinc- $\beta$-octaethylporphyrin (ZnOEP) units. XPS analyses and UV-visible absorption measurements have been carried out before and after incorporation of $\mathbf{P}_{\mathbf{5}} \mathbf{W}_{\mathbf{3 0}}$. It was expected that this species could potentially behave in the polymer as an electron relay between the excited ZnOEP (donor) and the viologen (or bis-viologen) acceptors which could retard the charge recombination. We have systematically investigated photocurrent generation with poly-ZnOEP and of poly-ZnOEP/P5 $\mathbf{P}_{30}$ under visible-light illumination in the presence of $\mathrm{I}_{3}^{-} / \mathrm{I}^{-}$used as redox mediator in acetonitrile as well as in aqueous medium.

\section{Experimental}

Materials. All solvents were of reagent grade quality and used without further purification. The zinc$\beta$-octaethylporphyrin (ZnOEP) and ligand 4,4'-bipyridine (4,4'-bpy) was purchased from SigmaAldrich and used without further purification. The 1,1"-(1,3-propanediyl)bis-4,4'-bipyridinium hexaflurophosphate salt $\left(\mathrm{bpy}^{+}-\mathrm{CH}_{2}-\mathrm{CH}_{2}-\mathrm{CH}_{2}{ }^{+} \mathrm{bpy} \cdot 2 \mathrm{PF}_{6}{ }^{-}\right)$was synthesized according to procedures 
described in literature. $\mathbf{1 4}$ Preyssler-type polyoxometalate $\mathbf{P}_{5} \mathbf{W}_{\mathbf{3 0}}$, namely $\mathrm{K}_{12.5} \mathrm{Na}_{1.5}\left[\mathrm{NaP}_{5} \mathrm{~W}_{30} \mathrm{O}_{110}\right] .15 \mathrm{H}_{2} \mathrm{O}$, were prepared as previously reported. ${ }^{15}$

Electrochemistry and photoelectrochemistry. Voltammetric and electrochemical impedance measurements have been performed with a standard three-electrode system using a PARSTAT 2273 potentiostat. Glassy carbon or single-side coated indium-tin-oxide (ITO, SOLEMS, $25-35 \Omega / \mathrm{cm}^{-2}$ ) electrodes, with a surface of about $1 \mathrm{~cm}^{2}$ has been used as working electrode. A platinum wire has been used as auxiliary electrode. The reference electrode was a saturated calomel electrode (SCE). It was electrically connected to the solution by a junction bridge filled with the electrolyte. Photoelectrochemical responses for films were obtained by on-off light illumination of a $300 \mathrm{~W} \mathrm{Xe}$ arc lamp (with $\lambda>385 \mathrm{~nm}$ long pass filter) in acetonitrile containing $5 \mathrm{mmol} . \mathrm{L}^{-1}$ of $\mathrm{I}_{2}$ and $0.5 \mathrm{~mol} . \mathrm{L}^{-1}$ of NaI with two-electrode system. In solution $\mathrm{I}_{2}$ reacts with $\mathrm{I}^{-}$to give $\mathrm{I}_{3}{ }^{-} \mathrm{I}_{3}{ }^{-}$and $\mathrm{I}^{-}$anions act as reversible redox mediator and also as electrolyte in order to improve the conductivity and thus increase the current magnitude.

UV-visible Spectroscopic Measurements. UV-vis absorption spectra of the copolymers deposited on ITO or in DMF solution have been recorded on an Agilent 8453 spectrophotometer.

X-ray Photoelectron Spectroscopy (XPS). XPS experiments were carried out on a RBD upgraded PHI-5000C ESCA system (Perkin-Elmer) with MgKR radiation $(h=1253.6 \mathrm{eV})$ or Al KR radiation $(h$ $=1486.6 \mathrm{eV}$ ). In general, the $\mathrm{X}$-ray anode was run at $250 \mathrm{~W}$ and the high voltage was kept at $14.0 \mathrm{kV}$ with a detection angle at $54^{\circ}$. The pass energy was fixed at $23.5,46.95$, or $93.90 \mathrm{eV}$ to ensure sufficient resolution and sensitivity. The base pressure of the analyzer chamber was about $5 \times 10^{-8} \mathrm{~Pa}$. The sample was directly pressed to a self-supported disk $(10 \mathrm{x} 10 \mathrm{~mm})$ and mounted on a sample holder then transferred into the analyzer chamber. The whole spectra $(0-1100 \mathrm{eV})$ and the narrow spectra of all the elements with higher resolution were both recorded by using RBD 147 interface (RBD Enterprises, 
U.S.A.) through the Auger Scan 3.21 software. Binding energies were calibrated by using the containment carbon $(\mathrm{C} 1 \mathrm{~s}=284.6 \mathrm{eV})$. The data analysis was implemented by using the RBD Auger Scan 3.21 software provided by RBD Enterprises or XPS Peak4.1 provided by Raymund W.M. Kwok (The Chinese University of Hongkong, China).

Synthesis of the poly-ZnOEP films. Electropolymerizations have been carried out under an argon atmosphere using a 0.1 mol. $\mathrm{L}^{-1}$ solution of $\mathrm{NBu}_{4} \mathrm{PF}_{6}$ in $\mathrm{CH}_{3} \mathrm{CN} / 1,2-\mathrm{C}_{2} \mathrm{H}_{4} \mathrm{Cl}_{2}$ (1/4) containing $2.5 \times$ $10^{-4} \mathrm{~mol} . \mathrm{L}^{-1}$ of $\mathbf{Z n O E P}$ and $2.5 \times 10^{-4} \mathrm{~mol} . \mathrm{L}^{-1}$ of $4,4^{\prime}-$ bipyridine or bpy ${ }^{+}-\mathrm{CH}_{2}-\mathrm{CH}_{2}-\mathrm{CH}_{2}{ }^{+}$bpy $\cdot 2 \mathrm{PF}_{6}{ }^{-}$. Electropolymerization is carried out at a fixed potential $+1.90 \mathrm{~V}$ versus $\mathrm{SCE}$ at various deposition time. However, iterative scan between $-0.90 \mathrm{~V}$ and $2.00 \mathrm{~V} v s$. SCE or $-1.30 \mathrm{~V}$ and $+2.00 \mathrm{~V}$ vs. SCE, in the case of 4,4'-bipyridine or bpy ${ }^{+}-\mathrm{CH}_{2}-\mathrm{CH}_{2}-\mathrm{CH}_{2}{ }^{+}$bpy $2 \mathrm{PF}_{6}{ }^{-}$respectively, leads also to the formation of the co-polymer with viologen or bis-viologen spacers (Fig. S1 in ESI).

After electropolymerization, the modified working electrodes were systematically washed in $\mathrm{CH}_{3} \mathrm{CN}$ in order to remove traces of the monomers and of the excess of the $\mathrm{NBu}_{4} \mathrm{PF}_{6}$ salt present on the deposited films.

\section{Synthesis of the hybrid films poly-ZnOEP/P5 $\mathrm{W}_{30}$.}

Poly-ZnOEP/P5 $\mathbf{W}_{30}$ films have been prepared in two steps. First, the poly-ZnOEP polymers have been obtained using the protocol described below using a 0.1 mol. $\mathrm{L}^{-1}$ solution of $\mathrm{NBu}_{4} \mathrm{PF}_{6}$ in $\mathrm{CH}_{3} \mathrm{CN} / 1,2-\mathrm{C}_{2} \mathrm{H}_{4} \mathrm{Cl}_{2}(1 / 4)$ containing $2.5 \times 10^{-4}$ mol.L $\mathrm{L}^{-1}$ of $\mathbf{Z n O E P}$ and $2.5 \times 10^{-4}$ mol.L ${ }^{-1}$ of $4,44^{\prime}-\mathrm{bpy}$ (poly-ZnOEP1) or bpy ${ }^{+}-\mathrm{CH}_{2}-\mathrm{CH}_{2}-\mathrm{CH}_{2}{ }^{+}$bpy $2 \mathrm{PF}_{6}{ }^{-}$(poly-ZnOEP2) under an argon atmosphere (Scheme 1). In this case, electropolymerization was carried out in a potentiostatic regime at a fixed potential of $+1.90 \mathrm{~V}$ versus SCE using various time of deposition (between $5 \mathrm{~s}$ and $180 \mathrm{~s}$ ). After completion of the polymerization, the ITO electrodes were systematically washed with acetonitrile to remove traces of the monomers and of the salt present in the film. Second, after drying, $\mathbf{P}_{\mathbf{5}} \mathbf{W}_{\mathbf{3 0}}$ was incorporated by metathesis, which involved exchanging the $\mathrm{PF}_{6}{ }^{-}$counter anions by immersion of the modified electrodes in 0.1 mmol.L $\mathrm{L}^{-1}$ aqueous $\mathrm{K}_{12.5} \mathrm{Na}_{1.5}\left[\mathrm{NaP}_{5} \mathrm{~W}_{30} \mathrm{O}_{110}\right]$ solution using various soaking 
times. Then, the modified electrodes were further cleaned by dipping into Millipore Q water to obtain the targeted poly-ZnOEP/P5 $\mathbf{3} 30$ hybrid films.

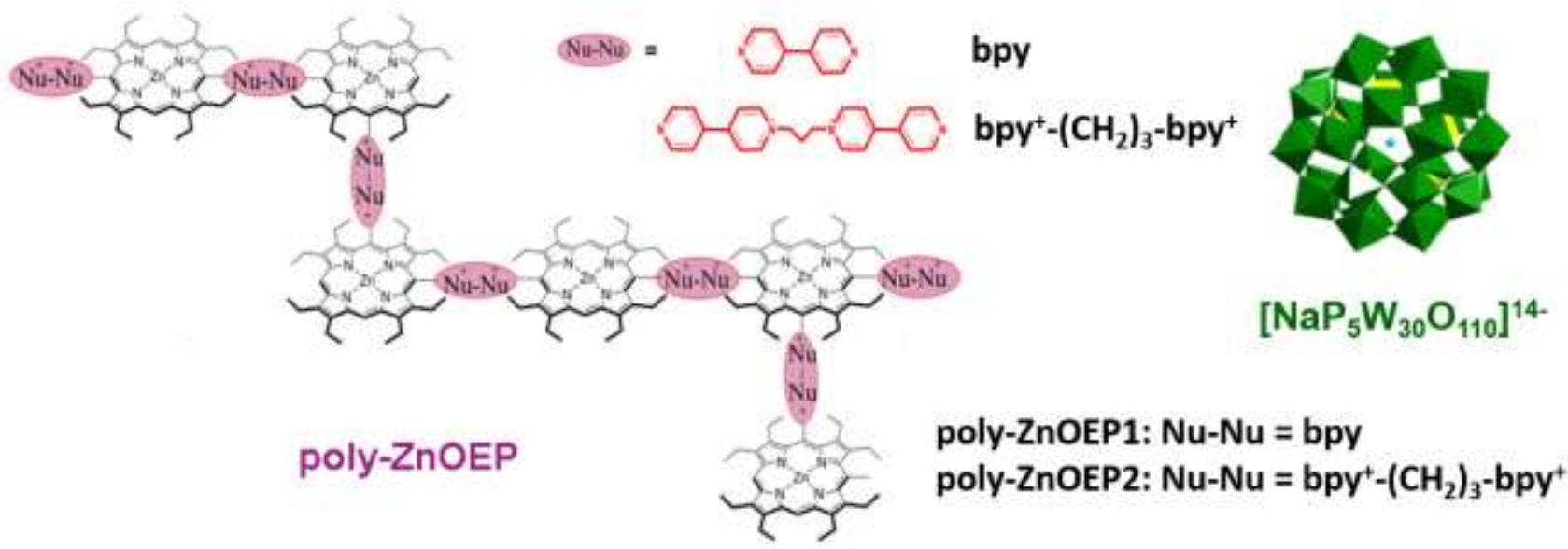

Scheme 1. Structures of the investigated poly-ZnOEP polymers featuring viologen or bis-viologen spacers and a $\mathrm{K}_{12.5} \mathrm{Na}_{1.5}\left[\mathrm{NaP}_{5} \mathbf{W}_{30} \mathrm{O}_{110}\right]$ Preyssler-type polyoxometalate.

\section{Electrochemical quartz crystal measurement (EQCM/QCM).}

A QCA-922 (SEIKO EG\&G instrument) system combined with Versa STAT 3 was used for carrying out simultaneous electrochemical quartz crystal (EQCM) and cyclic voltammetric measurements. The electrochemical cell was assembled in a glove box using an ITO AT-cut quartz crystal resonator (mirror finished; resonant frequency, $9.08 \mathrm{MHz} \pm 50 \mathrm{kHz} ; \mathrm{A}=0.2 \mathrm{~cm}^{2}$; SEIKO EG\&G., LTD) as working electrode, a platinum wire as counter electrode, and an $\mathrm{Ag} / \mathrm{AgCl}$ wire as a quasi-reference electrode. The solution used here is the same as the one used for electropolymerization of the copolymers on larger ITO electrodes. Iterative scans were conducted at a scan rate of $100 \mathrm{mV} \mathrm{s}^{-1}$ at room temperature with simultaneous recording of the quartz resonance frequency. The change of the quartz resonance frequency $(\Delta \mathrm{f})$ was converted into the mass change $(\Delta \mathrm{m})$ on the ITO-coated quartz during iterative cycling by applying Sauerbrey's equation (Eq. 1):

$$
\Delta \mathrm{f}=-2 \mathrm{f}_{0}^{2} \cdot \Delta \mathrm{m} / \mathrm{A}(\mu \cdot \rho)^{1 / 2} \quad(\text { Equation } 1)
$$


where $\mathrm{f}_{0}$ is the resonant frequency of the fundamental mode, $\rho$ is density of the crystal $\left(2.684 \mathrm{~g} . \mathrm{cm}^{-3}\right)$, A is working area $\left(0.2 \mathrm{~cm}^{2}\right)$ of the ITO quartz crystal resonator, $\mu$ is shear modulus of quartz $\left(2.947 \times 10^{11} \cdot \mathrm{m}^{-1} \cdot \mathrm{s}^{-2}\right)$. The Sauerbrey's equation (Eq. 1) can be used to calculate the mass of deposit $\Delta \mathrm{m}$ since our deposition yields a rigid and evenly distributed mass on the surface of the resonator, and the relative frequency variation is less than $2 \%$ of its absolute value.

\section{Results and Discussion}

\subsection{Fabrication and characterization of poly-ZnOEP films with viologen or bis-viologen spacers}

\subsubsection{Electropolymerization of poly-ZnOEP films with viologen or bis-viologen spacers monitored by EQCM}

The reactivity of oxidized porphyrins can be advantageously exploited to generate a wide range of poly-porphyrin materials as long as a bifunctional nucleophile such as a 4,4'-bipyridine is used. ${ }^{\mathbf{1 6}}$ Electropolymerization is carried out at a sufficiently high positive potential to produce doubly oxidized porphyrins (dication) which are readily reacting with the viologen-containing spacers to produce the targeted copolymers. Mono-substituted porphyrins can be obtained from the mono oxidized radical cations but electropolymerization requires the formation of porphyrin dications, most probably due to kinetic issues (porphyrin dications react more rapidly with pyridyl groups than the radical cation). The previously reported $\mathrm{E}\left(\mathrm{EC}_{\mathrm{N} \text { meso }} \mathrm{EC}_{\mathrm{B}}\right)_{\mathrm{n}} \mathrm{E}$ process has been proposed to explain the electropolymerization process where $\mathrm{C}_{\mathrm{N} \text { meso }}$ relates to the nucleophilic attack at the meso position of the porphyrin to form an isoporphyrin intermediate. ${ }^{\mathbf{1 6 b}, \mathbf{1 7}}$ This latter is then oxidized (electrochemical step) and the hydrogen atom initially located on the meso-carbon is released (chemical step $\mathrm{C}_{\mathrm{B}}$ ). The corresponding global reaction is written in Eq. 2 assuming that only the bisubtitution on the ZnOEP porphyrin occurs at two of the four meso positions (cis or trans bisubstitution: substitution on the carbons $\mathrm{C} 5$ and $\mathrm{C} 10$ or C5 and C15 respectively, Scheme 1): 


$$
(\mathrm{n}+1) \mathrm{ZnOEP}+(\mathrm{n}+1) \mathrm{Py}-\mathrm{Py} \rightarrow \mathrm{ZnOEP}-\left(\mathrm{Py}^{+}-\mathrm{Py}^{+}-\mathrm{ZnOEP}\right)_{\mathrm{n}}-\mathrm{Py}^{+}-\mathrm{Py}+(2 \mathrm{n}+1) \mathrm{H}^{+}+(4 \mathrm{n}+2) \mathrm{e}^{-}
$$

(Equation 2)

The copolymer can thus only be obtained after generation of the porphyrin dications by iterative scans (Fig. S1, ESI) or by potentiostatic electrolysis at $+1.90 \mathrm{~V} v s$. SCE (Fig. 1). Previous studies have shown that scanning the electrode potential between $-0.9 \mathrm{~V}$ and $+2.0 \mathrm{~V}$ or between $-1.3 \mathrm{~V}$ and $+2.0 \mathrm{~V} v s$. SCE for bpy or bpy ${ }^{+}-\mathrm{CH}_{2}-\mathrm{CH}_{2}-\mathrm{CH}_{2}-{ }^{+} \mathrm{bpy} \cdot 2 \mathrm{PF}_{6}{ }^{-}$respectively, allows to reduce the protons released by the electropolymerization. $\mathrm{H}^{+}$accumulates in solution when scanning is limited to the positive potential window or when polymerization is achieved in an electrolysis regime at an applied potential of $+1.9 \mathrm{~V} v s$. SCE. Even in these cases, we found that $\mathrm{H}^{+}$does not affect the coating process. We have also demonstrated, mainly by UV-vis absorption spectroscopy, that the metal ion remains in the porphyrin ring during electropolymerization. In support of this assertion, we found that the UV-visible absorption spectra of mother solutions, containing ZnOEP and the nucleophilic spacer (4,4'-bpy or bpy ${ }^{+}-\mathrm{CH}_{2}-\mathrm{CH}_{2}-\mathrm{CH}_{2}{ }^{+}$bpy $2 \mathrm{PF}_{6}^{-}$), shows no evidence of demetallation of the starting $\mathbf{Z n O E P}$ even after deposition of several films or that the spectroscopic signature of ZnOEP is retained in films produced from the iterative method.

Electropolymerizations could thus be carried out under an argon atmosphere by iterative scans performed in $0.1 \mathrm{~mol} \mathrm{~L}^{-1}$ solutions of tetrabutylammonium hexafluorophosphate in $\mathrm{CH}_{3} \mathrm{CN} / 1$,2$\mathrm{C}_{2} \mathrm{H}_{4} \mathrm{Cl}_{2}(1: 4)$ containing $\mathbf{Z n O E P}\left(0.25 \mathrm{mmol} . \mathrm{L}^{-1}\right)$ and a pyridine-based nucleophile such as bpy or bpy ${ }^{+}-\mathrm{CH}_{2}-\mathrm{CH}_{2}-\mathrm{CH}_{2}{ }^{+}$bpy $2 \mathrm{PF}_{6}^{-}\left(0.25 \mathrm{mmol} . \mathrm{L}^{-1}\right)$. The evolution of the $\mathrm{CV}$ curves recorded during the electropolymerization of $\mathbf{Z n O E P}$ with 4,4'-bipy and bpy ${ }^{+}-\mathrm{CH}_{2}-\mathrm{CH}_{2}-\mathrm{CH}_{2}{ }^{+}$bpy $2 \mathrm{PF}_{6}{ }^{-}$is shown in the ESI section (Fig. S1).

Deposition of poly-ZnOEP1 and poly-ZnOEP2 onto the electrode surface can also be achieved in a potentiostatic regime upon setting the electrode potential at $+1.90 \mathrm{~V} v s$. SCE. The associated mass change $(\Delta \mathrm{m})$ was calculated from the quartz resonance frequency $(\Delta \mathrm{f})$ recorded at an ITO AT-cut quartz crystal resonator of an Electrochemical Quartz Crystal Microbalance (EQCM). Deposition of the polymer on the quartz resonator during electrolysis is revealed by a large decrease of the quartz 
resonance frequency $(\Delta \mathrm{f})$ over time. The associated changes in mass at the working electrode could be quantified from the changes in the quartz resonance frequency $(\Delta \mathrm{f})$ using Sauerbrey's equation. ${ }^{\mathbf{1 8}}$ Calculations performed after 180 seconds of electrolysis led to loadings of 7.9 and $5.7 \mu \mathrm{g} . \mathrm{cm}^{-2}$ for poly-ZnOEP1 and poly-ZnOEP2, respectively. The calculated surface coverage $\Gamma$ in mole of repeat

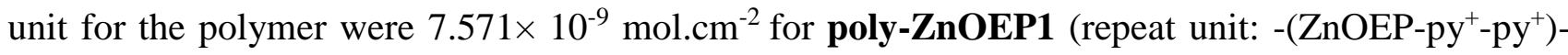
$\left.2 \mathrm{PF}_{6}^{-}\right)$and $4.68 \times 10^{-9} \mathrm{~mol} . \mathrm{cm}^{-2}$ poly-ZnOEP2 (repeat unit: $-\left(\mathrm{ZnOEP}-\mathrm{py}^{+}-\mathrm{py}^{+}-\mathrm{CH}_{2}-\mathrm{CH}_{2}-\mathrm{CH}_{2}-\mathrm{py}^{+}-\right.$ $\left.\left.\mathrm{py}^{+}\right)-4 \mathrm{PF}_{6}^{-}\right)$. It shows that in the same conditions, poly-ZnOEP2 is less deposited.
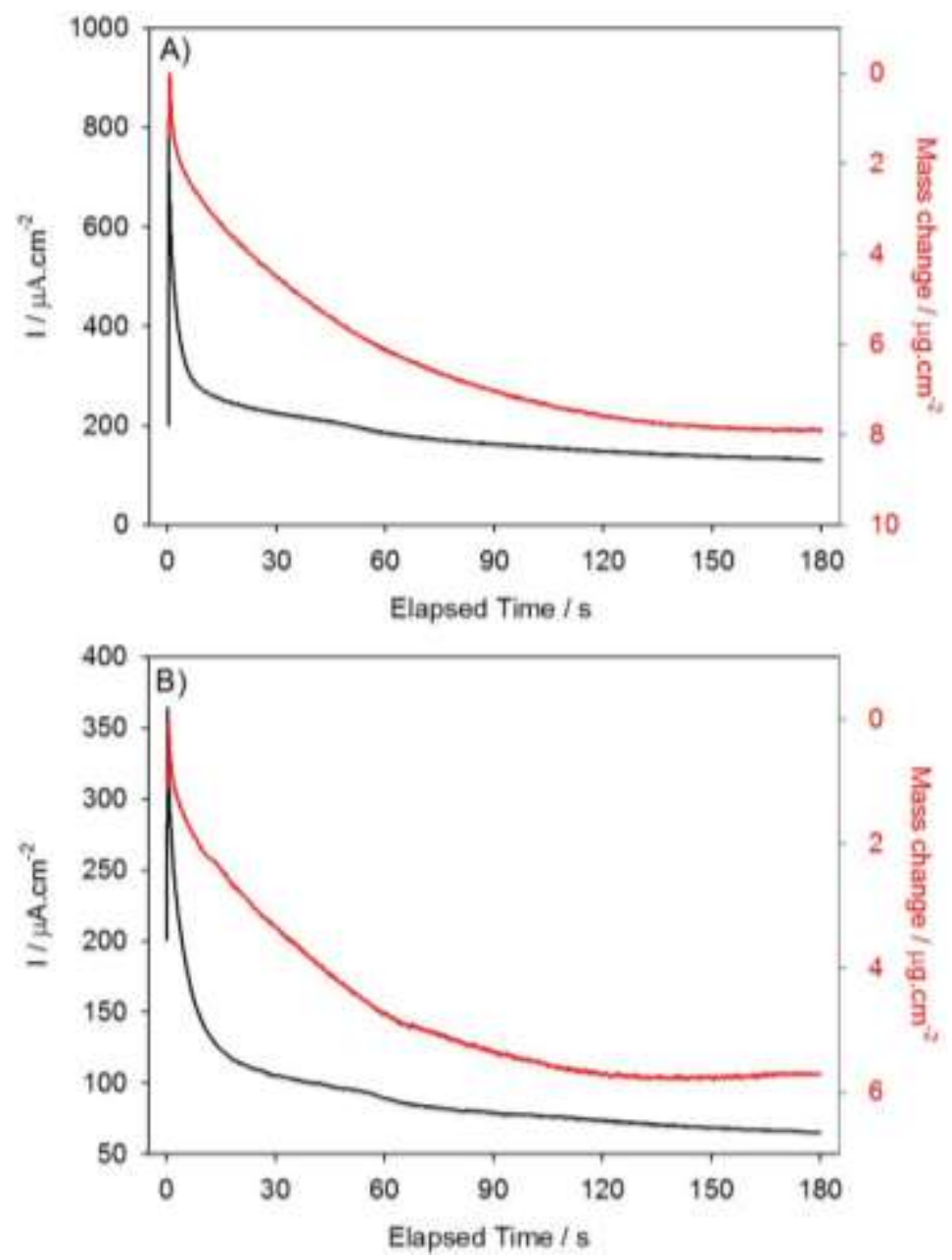

Fig. 1. Fixed potential deposition (+1.90 V vs. SCE) and electrochemical quartz crystal microbalance measurements during the electropolymerization of 0.25 mmol.L $\mathrm{L}^{-1}$ of A) $\mathbf{4 , 4} \mathbf{4}^{\prime}-\mathbf{b p y}$ and B) $\mathbf{b p y}^{+}-\mathbf{C H}_{2}$ CH2-CH ${ }_{2}{ }^{+}$bpy 2 PF6 $_{6}{ }^{-}$with 0.25 mmol. $\mathrm{L}^{-1} \mathbf{Z n O E P}$ in $\mathrm{CH}_{3} \mathrm{CN} / 1,2-\mathrm{C}_{2} \mathrm{H}_{4} \mathrm{Cl}_{2}$ (1/4) in the presence of 0.1 mol L ${ }^{-1}$ TBAPF $_{6}$. Working electrode: ITO $\left(\mathrm{A}=0.2 \mathrm{~cm}^{2}\right)$ deposited on a $9.08 \mathrm{MHz}$ AT-cut quartz crystal. 


\subsection{2. $U V$-visible spectroscopy}

The UV-visible absorption spectra of the ZnOEP monomer in solution and of the copolymers deposited on ITO are shown for comparison in Figure 2. These data are also collected in Table 1. This superposition reveals that the Soret band, attributed to the main porphyrin-based $\pi-\pi^{*}$ electronic transition, is much broader and more red-shifted for the two copolymers poly-ZnOEP1 and polyZnOEP2 (onto ITO electrode) than for the ZnOEP (Table 1). Such modifications can be interpreted upon considering the existence of intra- and intermolecular exciton-coupling between the porphyrin units within the polymer. ${ }^{19}$ These changes can also be explained by a greater deformation of the macrocycles within the copolymer. Furthermore, the red-shift of the Soret band can also be attributed to the electron-withdrawing effects of the viologen substituents on the porphyrin rings. ${ }^{19 a}$
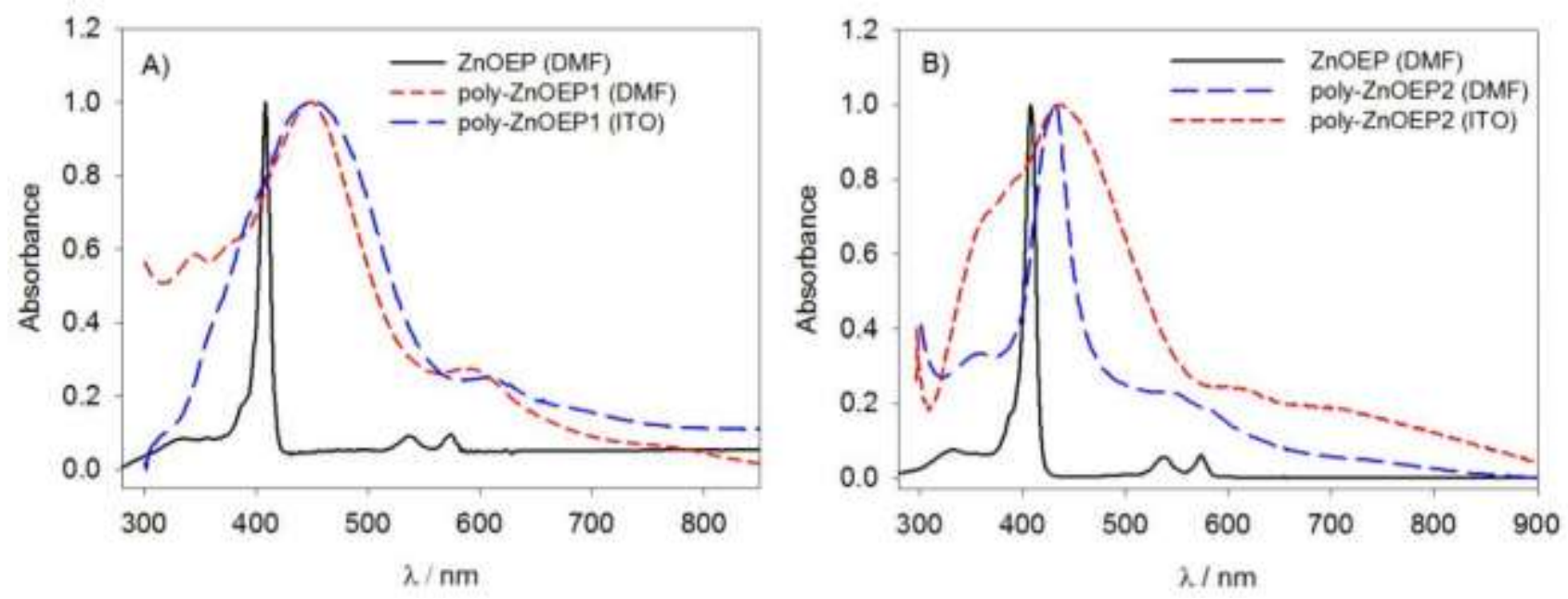

Fig. 2. UV-Vis normalized absorption spectrum of A) poly-ZnOEP1 (obtained after 25 iterative scans between $-0.9 \mathrm{~V}$ and $2.0 \mathrm{~V}, \mathrm{v}=0.2 \mathrm{~V} . \mathrm{s}^{-1}$ ) and of B) poly-ZnOEP2 (obtained after 25 iterative

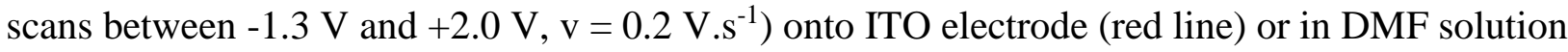
(blue line) compared to ZnOEP (black line) in DMF.

The films produced by electropolymerization were found to be fully soluble in DMF. Analysis of the resulting solutions by UV-Vis absorption spectroscopy revealed a much sharper Soret band than that 
recorded on the solid film, the latter effect being clearly more pronounced for poly-ZnOEP2 (Fig. 2B) than for poly-ZnOEP1 (Fig. 2A). Such difference has been attributed to the existence of weaker exciton-coupling between porphyrins in poly-ZnOEP2, likely due to the larger flexibility of the polymer.

Similar optical spectra were obtained using films obtained using applied potential of $1.9 \mathrm{~V} v s$. SCE (Fig. 3).

Table 1 UV-visible spectral data for $\mathbf{Z n O E P , ~ 4 , 4 ' - b p y ~ a n d ~}$ bpy $^{+}-\mathrm{CH}_{2}-\mathrm{CH}_{2}-\mathbf{C H}_{2}{ }^{-}{ }^{+}$bpy $\mathbf{2} \mathbf{P F}_{6}{ }^{-}$in acetonitrile, poly-ZnOEP1/P5 $\mathbf{W}_{30}$ and poly-ZnOEP2/P5 $\mathbf{W}_{30}$ on ITO. Under bracket: molar extinction coefficient $\left(\varepsilon / 10^{3}\right.$ L.M.cm $\left.{ }^{-1}\right)$.

\begin{tabular}{|c|c|c|c|}
\hline Compound & Soret band/nm & $\mathrm{Q}$ bands/nm & $\pi-\pi^{*}$ Band $/ \mathbf{n m}$ \\
\hline \multirow[t]{2}{*}{ ZnOEP } & $404(414.2)$ & $533(187.1)$ & \\
\hline & & $568(199.8)$ & \\
\hline 4,4'-bpy & & & $285(13.4)$ \\
\hline $\mathrm{bpy}^{+}\left(\mathrm{CH}_{2}\right)_{3} \mathrm{bpy}^{+} 2 \mathrm{PF}_{6}^{-}$ & & & $266(40.8)$ \\
\hline poly-ZnOEP1 & 431 & 612 & \\
\hline poly-ZnOEP2 & 433 & 611,709 & \\
\hline poly-ZnOEP1/P5W30 & 435 & 616 & \\
\hline poly-ZnOEP2/P5W30 & 434 & 608 & \\
\hline
\end{tabular}

We have also examined the effect of various experimental parameters used for electropolymerization on the properties of the ITO coated polymers. Different modified electrodes have been grown at +1.90 V vs. SCE upon varying the deposition time (Fig. 3). Plotting the absorbance of the Soret band recorded for poly-ZnOEP1 and poly-ZnOEP2 as a function of deposition time (inset of Figure 3) leads to comparable curves. A plot of the absorbance at $\lambda=433 \mathrm{~nm}$ and $\lambda=426 \mathrm{~nm}$ (Soret band of polyZnOEP1 and of poly-ZnOEP2 respectively) as a function of the deposition time (inset of Figure $3 \mathrm{AB}$ ) shows a nearly linear increase of the absorbance of the film (i.e. the thickness) versus the time of deposition reaching one plateau for time upper than 120 seconds. 
Similar conclusions could be drawn from data collected using iterative scans for deposition.
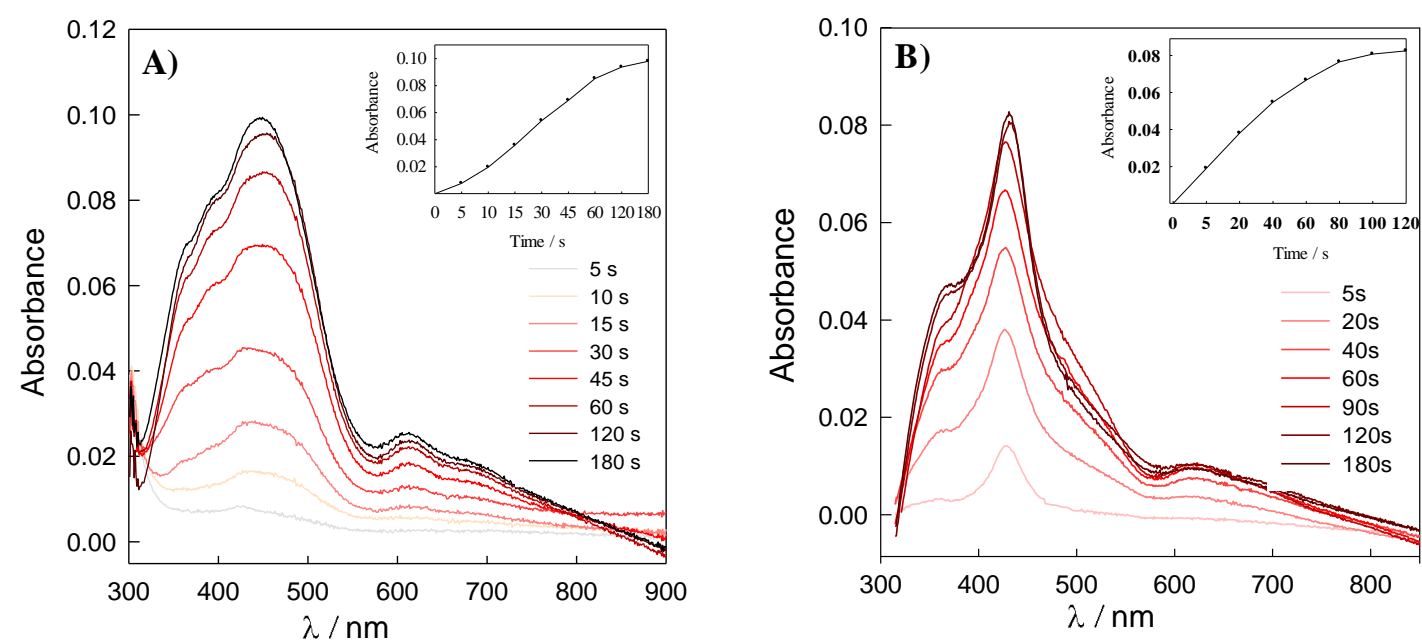

Fig. 3. UV-vis absorption spectra of A) poly-ZnOEP1 and B) poly-ZnOEP2 obtained after different deposition time under $+1.90 \mathrm{~V}$ vs. SCE. Inset: a plot of the absorbance at $\lambda=433 \mathrm{~nm}$ and $\lambda=426 \mathrm{~nm}$ (Soret band of poly-ZnOEP1 and poly-ZnOEP2) as a function of the time of deposition.

\subsubsection{Cyclic voltammetric investigations of the copolymeric films}

Electroactive polymers deposited on ITO surfaces have been characterized by electrochemical methods. After deposition of the polymers at fixed potential $(+1.90 \mathrm{~V} v s$. SCE), the modified electrodes were removed from the electrochemical cell, washed with $\mathrm{CH}_{3} \mathrm{CN}$ and used as working electrode in a clean electrolytic solution containing only the solvent and the supporting electrolyte (Fig. 4). A detailed discussion on the redox behaviour of poly-ZnOEP1 can be found in a previous report. ${ }^{16}$ In the present study involving deposition at an applied potential of $+1.9 \mathrm{~V} v s$. SCE, the investigation has been conducted in a 1,2- $\mathrm{C}_{2} \mathrm{H}_{4} \mathrm{Cl}_{2} / \mathrm{CH}_{3} \mathrm{CN}$ (4/1) solution (same mixing solvent used for the electropolymerization). The reduction peaks centered at ca. $0.04 \mathrm{~V}$ (peak I), $-0.24 \mathrm{~V}$ (peak II) and $0.55 \mathrm{~V}$ (peak III) corresponds to the first $\left(\mathrm{V}^{2+} \rightarrow \mathrm{V}^{+}\right.$, peak I) and second reduction $\left(\mathrm{V}^{+} \rightarrow \mathrm{V}^{0}\right.$, peaks II and III) of the viologens spacers (Table 2, Fig 4A and Fig. S2A). 
The splitting of the wave attributed to the reduction of the viologen units (peaks II and III) most probably arises from the specific copolymer's structure and from communication/interaction processes occurring between neighboring redox active fragments (viologen radical cations, $\mathrm{V}^{+\bullet}$ ) in the chain or between chains giving intra- or intermolecular interactions.

The poly-ZnOEP2 film was also studied in the electrolyte used for electropolymerization (1,2$\mathrm{C}_{2} \mathrm{H}_{4} \mathrm{Cl}_{2} / \mathrm{CH}_{3} \mathrm{CN}$ (4/1) solution (Fig 4B and Fig. S2B). ${ }^{20}$ The first well defined, bell-shaped, reduction wave observed at $-0.12 \mathrm{~V} v$ s. SCE (peak I) is attributed to the formation of viologen radical cations in the polymer $\left(\mathrm{V}^{2+} \rightarrow \mathrm{V}^{+\bullet}\right)$. The second viologen-centered electron transfer $\left(\mathrm{V}^{+\bullet} \rightarrow \mathrm{V}^{0}\right)$ is then observed as two successive waves at $-0.52 \mathrm{~V}$ and $-0.66 \mathrm{~V}$ vs. SCE (peaks II and III).

The wave splitting is not observed for the first electron transfer leading to the formation of the bisradical $\mathrm{V}^{+\cdot}-\left(\mathrm{CH}_{2}\right)_{3}-\mathrm{V}^{+\cdot}$ (peak I) but only on the following redox processes yielding $\mathrm{V}^{+\cdot}-\left(\mathrm{CH}_{2}\right)_{3}-\mathrm{V}^{0}$ and $\mathrm{V}^{0}-\left(\mathrm{CH}_{2}\right)_{3}-\mathrm{V}^{0}$ in the copolymer poly-ZnOEP2 (peaks II and III respectively) as already observed in the case of poly-ZnOEP1. It should also be mentioned that similar behaviors have been observed when investigating poly-ZnOEP1 and poly-ZnOEP2 films (Fig. 4 and Table 2) in $\mathrm{CH}_{3} \mathrm{CN}(0.1$ mol.L $\left.{ }^{1} \mathrm{TBAPF}_{6}\right)$.
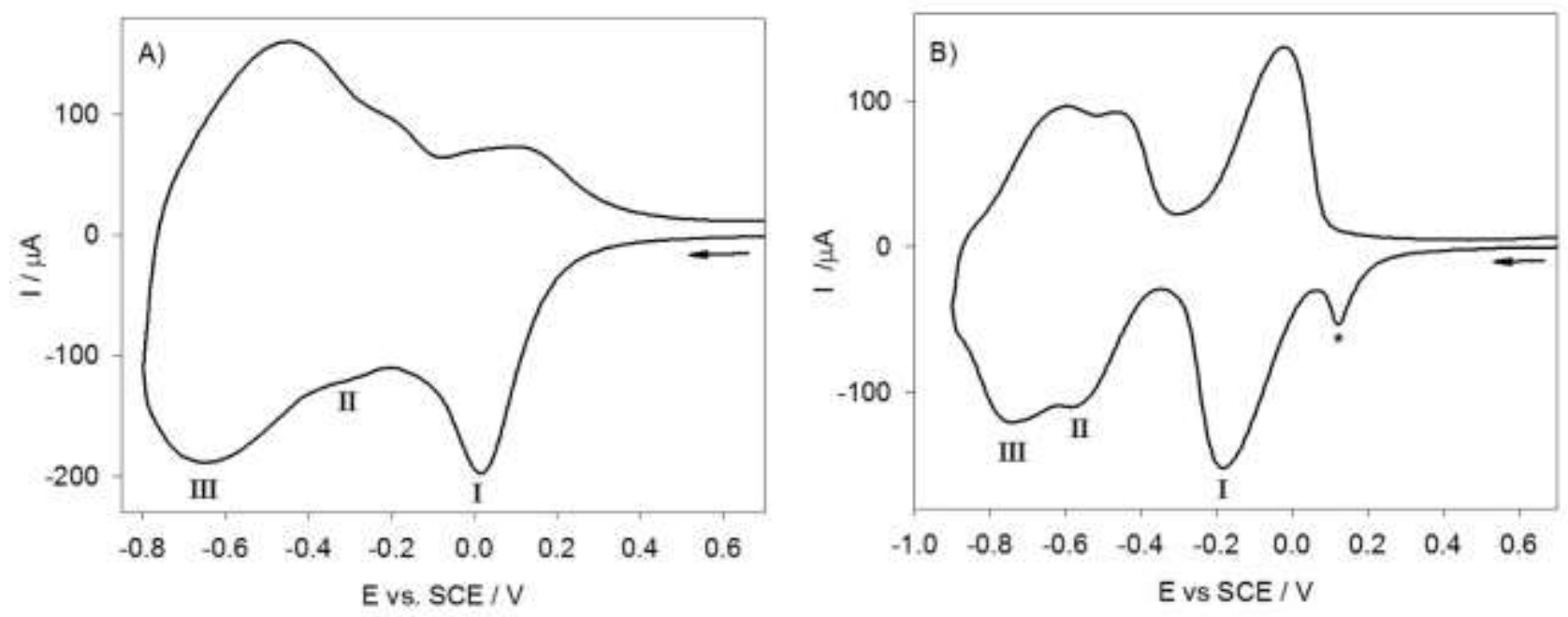

Fig. 4. Cyclic voltammograms of A) poly-ZnOEP1 and B) poly-ZnOEP2 film obtained after applied potential of $+1.90 \mathrm{~V} v$ s. SCE during $180 \mathrm{~s}$. in $\mathrm{CH}_{3} \mathrm{CN}$ and $0.1 \mathrm{~mol}^{-1} \mathrm{TBAPF}_{6}$. WE: ITO. $\mathrm{S}=1 \mathrm{~cm}^{2}$. $v=0.1 \mathrm{~V} \cdot \mathrm{s}^{-1} \cdot *$ reduction of the intermediate isoporphyrin. 
Electrochemical data versus ENH for $\mathbf{Z n O E P ,} \mathbf{b p y}^{+}-\mathbf{C H}_{2}-\mathbf{C H}_{2}-\mathbf{C H}_{2}{ }^{+}{ }^{-} \mathbf{b p y} \quad \mathbf{2 P F}_{6}{ }^{-}$,

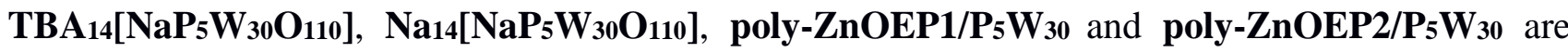
gathered in Table S3 (see ESI).

Table 2 Electrochemical data versus SCE for $\mathbf{Z n O E P , ~} \mathbf{b p y}^{+}-\mathbf{C H}_{2}-\mathbf{C H}_{2}-\mathbf{C H}_{2}{ }^{-}{ }^{+}$bpy $\mathbf{2 P F}_{6}$, $\mathrm{TBA}_{14}\left[\mathrm{NaP}_{5} \mathrm{~W}_{30} \mathrm{O}_{110}\right]$, Na14[NaP5 $\left.\mathrm{W}_{30} \mathrm{O}_{110}\right]$, poly-ZnOEP1/P5W 30 and poly-ZnOEP2/P5W30.

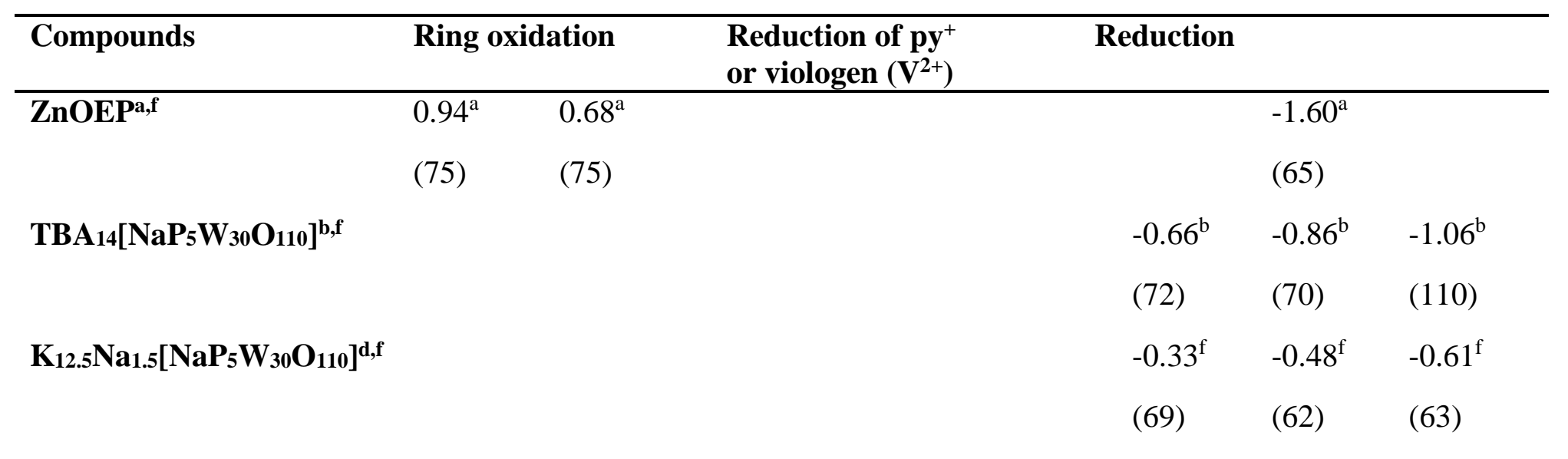

$1,2-\mathrm{EtCl}_{2} / \mathrm{CH}_{3} \mathrm{CN}(4 / 1)+\mathrm{TBAPF}_{6}$ poly-ZnOEP1 ${ }^{a}$

$0.04^{\mathrm{a}} \quad-0.24^{\mathrm{a}} \quad-0.55^{\mathrm{a}}$

(85) (86) (203)

poly-ZnOEP2 $^{\text {a }}$

$-0.12^{\mathrm{a}} \quad-0.52^{\mathrm{a}} \quad-0.66^{\mathrm{a}}$

$-1.33^{\mathrm{a}}$

$-1.58^{\mathrm{a}}$

(178)

(172) (170)

(63)

(51)

\begin{tabular}{|c|c|c|c|c|c|}
\hline \multicolumn{6}{|c|}{$\mathrm{CH}_{3} \mathrm{CN}+\mathrm{TBAPF}_{6}$} \\
\hline poly-ZnOEP1g & $1.56^{\mathrm{irr}, \mathrm{b}}$ & $0.99^{\text {irr,b }}$ & $\begin{array}{l}0.07^{b} \\
(114)\end{array}$ & $\begin{array}{l}-0.24^{\mathrm{b}} \\
(86)\end{array}$ & $\begin{array}{l}-0.55^{b} \\
(198)\end{array}$ \\
\hline poly-ZnOEP2g & $1.58^{\mathrm{irr}, \mathrm{b}}$ & $1.01^{\mathrm{irr}, \mathrm{b}}$ & $\begin{array}{l}-0.10^{b} \\
(158)\end{array}$ & $\begin{array}{l}-0.52^{\mathrm{b}} \\
(65)\end{array}$ & $\begin{array}{l}-0.67^{\mathrm{b}} \\
(147)\end{array}$ \\
\hline poly-ZnOEP1/P5W30 & $1.58^{\mathrm{irr}, \mathrm{b}}$ & $0.94^{\mathrm{irr}, \mathrm{b}}$ & $\begin{array}{l}0.05^{b} \\
(114)\end{array}$ & $\begin{array}{l}-0.25^{b} \\
(74)\end{array}$ & $\begin{array}{l}-0.54^{b} \\
(214)\end{array}$ \\
\hline poly-ZnOEP2/P5W30 & $1.58^{\mathrm{irr}, \mathrm{b}}$ & $1.01^{\mathrm{irr}, \mathrm{b}}$ & $\begin{array}{l}-0.13^{b} \\
(152)\end{array}$ & $\begin{array}{l}-0.51^{b} \\
(118)\end{array}$ & $\begin{array}{l}-0.68^{b} \\
(195)\end{array}$ \\
\hline \multicolumn{6}{|c|}{$\mathrm{CH}_{3} \mathrm{CN}+\mathrm{NaI}$} \\
\hline poly-ZnOEP1g & & & $\begin{array}{l}-0.24^{\mathrm{c}} \\
(31)\end{array}$ & $\begin{array}{l}-0.60^{c} \\
(105)\end{array}$ & $\begin{array}{l}-0.86^{\mathrm{c}} \\
(69)\end{array}$ \\
\hline
\end{tabular}




\begin{tabular}{|c|c|c|c|}
\hline poly-ZnOEP2g & $\begin{array}{l}-0.36^{c} \\
(60)\end{array}$ & $\begin{array}{l}-0.71^{\mathrm{c}} \\
(47)\end{array}$ & $\begin{array}{l}-0.83^{\mathrm{c}} \\
(57)\end{array}$ \\
\hline \multirow[t]{2}{*}{ poly-ZnOEP1/P5W ${ }_{30}^{\mathrm{g}}$} & $-0.33^{c}$ & $-0.60^{c}$ & $-0.85^{\mathrm{c}}$ \\
\hline & (41) & $(120)$ & $(60)$ \\
\hline \multirow[t]{2}{*}{ poly-ZnOEP2/P5 $\mathrm{W}_{30}{ }^{\mathrm{g}}$} & $-0.40^{\mathrm{c}}$ & $-0.72^{\mathrm{c}}$ & $-0.84^{\mathrm{c}}$ \\
\hline & (36) & (59) & (96) \\
\hline \multicolumn{4}{|l|}{$\mathrm{H}_{2} \mathrm{O}+\mathrm{NaI}$} \\
\hline poly-ZnOEP1 ${ }^{d}$ & $\begin{array}{l}-0.19^{d} \\
(110)\end{array}$ & $-0.52^{\mathrm{d}, \mathrm{h}}$ & $\begin{array}{l}-0.66^{\mathrm{d}} \\
(205)\end{array}$ \\
\hline \multirow[t]{2}{*}{ poly-ZnOEP2d } & $-0.57^{\mathrm{d}}$ & $-0.89^{d}$ & $-1.11^{\mathrm{d}}$ \\
\hline & $(172)$ & $(122)$ & $(213)$ \\
\hline \multirow[t]{2}{*}{ poly-ZnOEP1/P5W $\mathrm{W}_{30}^{\mathrm{d}, \mathrm{g}}$} & $-0.22^{\mathrm{d}}$ & $-0.49^{\mathrm{d}}$ & $-0.79^{d}$ \\
\hline & $(125)$ & $(102)$ & $(165)$ \\
\hline \multirow[t]{2}{*}{ poly-ZnOEP2/P5W30 } & $-0.37^{\mathrm{d}}$ & $-0.70^{\mathrm{d}}$ & $-0.87^{\mathrm{d}}$ \\
\hline & (70) & $(55)$ & (58) \\
\hline
\end{tabular}

${ }^{a}$ Potentials in V vs. SCE were obtained from cyclic voltammetry in $1,2-\mathrm{C}_{2} \mathrm{H}_{4} \mathrm{Cl}_{2} / \mathrm{CH}_{3} \mathrm{CN}(\mathbf{4} / \mathbf{1})$ containing $0.1 \mathrm{~mol} \mathrm{~L}^{-1} \mathrm{NBu}_{4} \mathrm{PF}_{6}$. Scan rate $=20 \mathrm{mV} \mathrm{s}^{-1} .{ }^{\mathrm{b}}$ Potentials in $\mathrm{V} v s$. SCE were obtained from cyclic voltammetry in acetonitrile containing $0.1 \mathrm{~mol} \mathrm{~L}^{-1} \mathrm{NBu}_{4} \mathrm{PF}_{6}$. Scan rate $=20 \mathrm{mV} \mathrm{s}^{-1}$. ${ }^{\mathrm{c}}$ Potentials in V vs. SCE were obtained from cyclic voltammetry in acetonitrile containing $0.1 \mathrm{~mol} \mathrm{~L}^{-1} \mathrm{NaI}$. Scan rate $=20 \mathrm{mV} \cdot \mathrm{s}^{-1} .{ }^{\mathrm{d}}$ Potentials in $\mathrm{V} v \mathrm{~s}$. SCE were obtained from cyclic voltammetry in $\mathbf{H}_{2} \mathbf{O}$ containing 0.1 mol L ${ }^{-1}$ NaI. Scan rate $=20 \mathrm{mV} \cdot \mathrm{s}^{-1}$. ${ }^{\mathrm{e}}$ Potentials in $\mathrm{V}$ vs. SCE were obtained from cyclic voltammetry in $\mathbf{H}_{2} \mathrm{O}$ containing $0.1 \mathrm{M} \mathrm{NEt}_{4} \mathrm{PF}_{6}$. Scan rate $=20 \mathrm{mV} \mathrm{s}^{-1}$. ${ }^{\mathrm{f}}$ Working electrode: glass carbon electrode. ${ }^{\mathrm{g}}$ Working electrode: $\mathrm{ITO}, \mathrm{S}=1 \mathrm{~cm}^{2}$. The given half-wave potentials are equal to $\mathrm{E}_{1 / 2}$ $=\left(\mathrm{E}_{\mathrm{pa}}+\mathrm{E}_{\mathrm{pc}}\right) / 2$. Under bracket: $\triangle \mathrm{E}_{\mathrm{p}}=\left|\mathrm{E}_{\mathrm{pa}}-\mathrm{E}_{\mathrm{pc}}\right|$ in $\mathrm{mV} .{ }^{\mathrm{h}}$ only the cathodic peak is detected.

\subsubsection{Film Morphology (Atomic Force Microscopy)}

The morphology of poly-ZnOEP1 and poly-ZnOEP2 obtained in potentiostatic regime at $\mathrm{E}_{\mathrm{app}}=1.9$ V vs. SCE during 180 seconds has been scrutinized by AFM (Fig. S3). Both copolymers appear on the surface as tightly packed coils with an average diameter of ca. 80-100 nm. The rms surface roughness of the two films are estimated at $2.4 \mathrm{~nm}$ for poly-ZnOEP1 and $2.9 \mathrm{~nm}$ for poly-ZnOEP2 (calculated from an area of $25.0 \mu \mathrm{m}^{2}$ ), which are is in agreement with the morphology already depicted for our previous copolymers. 


\subsubsection{Thickness measurement of polymeric films}

The thickness of these films (Fig. 5) have been estimated upon scratching the film with a metallic tip and comparing the height on each side of the scratch (Fig. 5BC). The thickness measured by AFM was found to increase with the deposition time to reach an upper limit value. This trend is reminiscent of the data recorded by UV-Vis absorption spectroscopy. For deposited time of 180 seconds; the thickness of both deposited copolymeric film gave about $31 \mathrm{~nm}$ and $25 \mathrm{~nm}$ for poly-ZnOEP1 and polyZnOEP2, respectively.
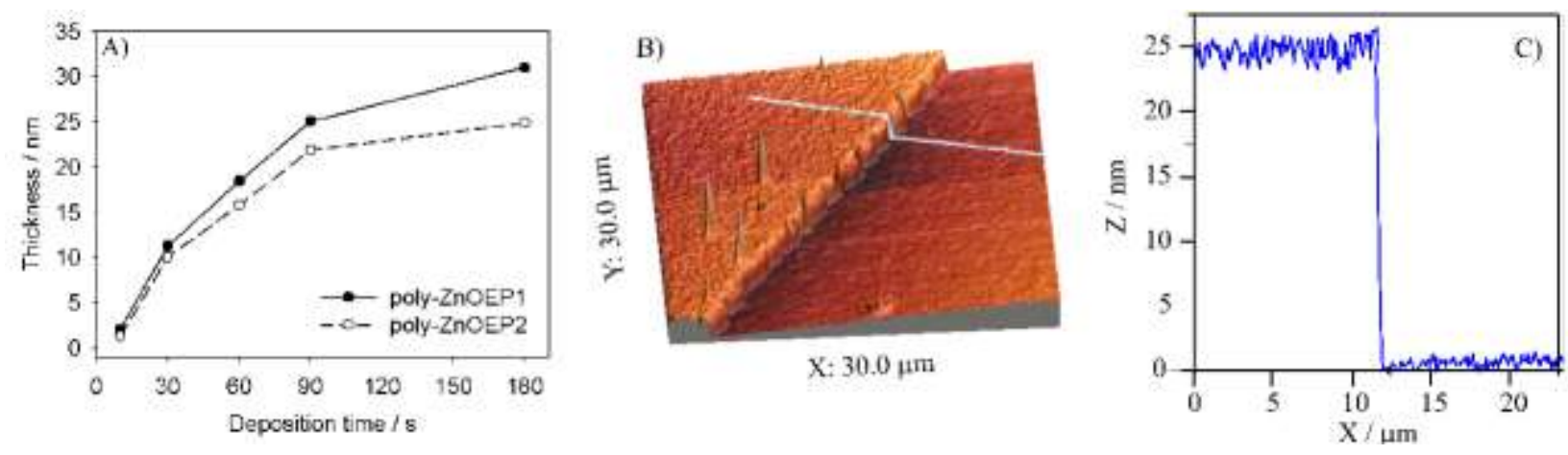

Fig. 5. A) thickness measurement, B) tapping mode AFM topography maps recorded with polyZnOEP2 (deposition on $+1.90 \mathrm{~V}$ vs. SCE, 180 seconds) and C) section analysis of the aggregate marked by a blue line.

\subsubsection{X-ray photoelectron spectra (XPS)}

XPS analyses have been carried out to determine the elemental composition of the two films. This type of characterization has been already used to determine the elemental composition of various porphyrins based films. XPS is not has proved very efficient to reveal the presence of given elements and their oxidation state within the films. The presence of $\mathrm{C}, \mathrm{N}, \mathrm{O}, \mathrm{Zn}, \mathrm{Na}, \mathrm{P}$, and $\mathrm{F}$ enables to confirm the presence of poly-ZnOEP1/P5W 30 (red line, Fig. 6). In poly-ZnOEP1 film, the Zn 2p3/2 (1022.8 eV) is assigned to the zinc atom in ZnOEP. Two different signals attributed to nitrogen atoms with different chemical states are observed at $402.6 \mathrm{eV}$, attributed to the ammonium counteractions, and at $399.7 \mathrm{eV}$ due to the viologen spacers and the nitrogen atoms present in the porphyrin as well the terminal pyridine (quite small quantity) respectively (Fig. 6C, black curve and Fig. S5). 
The P 2p3/2 (136.6 eV, Fig. 6E, black curve) and F 1s (686.8 eV, Fig. 6I black curve) is ascribed to counter ion $\mathrm{PF}_{6}$. While $\mathrm{O}$ 1s signal $\left(532.9 \mathrm{eV}\right.$ ) comes from $\mathrm{H}_{2} \mathrm{O}$ on the copolymer surface (Fig. 6D, black curve).-Similar behavior has been obtained for poly-ZnOEP2 film (Fig. S4 and Fig. S6).
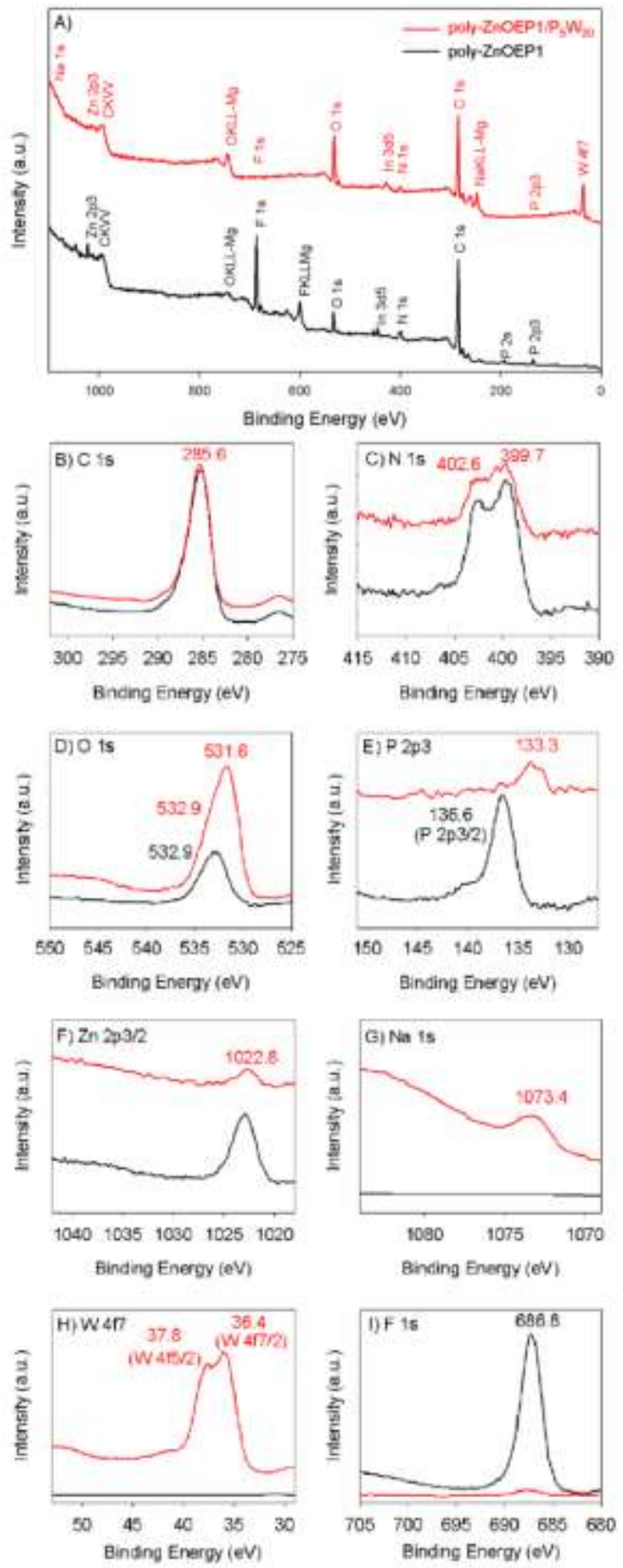

Fig. 6. XPS of poly-ZnOEP1 films on ITO with and without $\mathrm{P}_{5} \mathrm{~W}_{30}$. Global XPS spectra (A), C 1s (B), N 1s (C), O 1s (D), P 2p3 (E), Zn 2p3 (F), Na 1s (G), W 4f7 (H), F 1s (I). 


\subsection{Fabrication and characterization of two poly-ZnOEP-Preyssler type-POM composite films}

\subsubsection{Fabrication the poly-ZnOEP-Preyssler type-POM composite films}

Poly-ZnOEP/P5 $\mathbf{W}_{30}$ films have been prepared in two steps. The poly-ZnOEP copolymers have been obtained in a $0.1 \mathrm{~mol} \mathrm{~L}{ }^{-1}$ solution of $\mathrm{TBAPF}_{6}$ in $1,2-\mathrm{C}_{2} \mathrm{H}_{4} \mathrm{Cl}_{2} / \mathrm{CH}_{3} \mathrm{CN}$ (4/1) containing $2.5 \times 10^{-4}$ mol. $\mathrm{L}^{-1}$ of $\mathbf{Z n O E P}$ and $2.5 \times 10^{-4}$ mol.L ${ }^{-1}$ of $4,4^{\prime}-$ bpy (poly-ZnOEP1) or bpy ${ }^{+}-\mathrm{CH}_{2}-\mathrm{CH}_{2}-\mathrm{CH}_{2}-$ ${ }^{+}$bpy $2 \mathrm{PF}_{6}{ }^{-}$(poly-ZnOEP2) under an argon atmosphere. Electropolymerization is carried out at a fixed potential $+1.90 \mathrm{~V} v s$. SCE for 180 seconds.
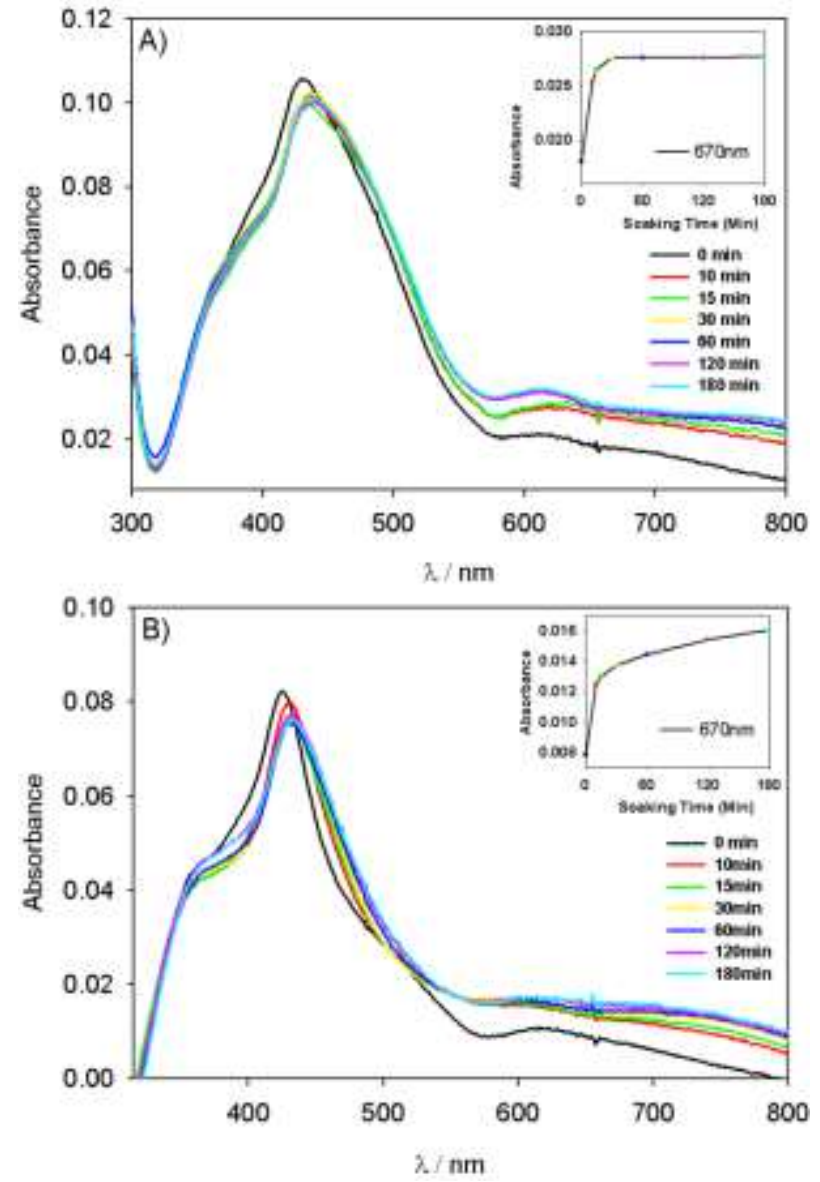

Fig. 7. UV-vis spectra of the modified ITO electrode with A) poly-ZnOEP1 and B) poly-ZnOEP2 after soaking in $0.1 \mathrm{mmol} . \mathrm{L}^{-1} \mathrm{~K}_{12.5} \mathrm{Na}_{1.5}\left[\mathrm{NaP}_{5} \mathrm{~W}_{30} \mathrm{O}_{110}\right]$ aqueous solution for $10 \mathrm{~min}, 15 \mathrm{~min}, 30 \mathrm{~min}$, $60 \mathrm{~min}, 120 \mathrm{~min}$, and $180 \mathrm{~min}$. Inset: absorbance intensity at $\lambda=670 \mathrm{~nm} v \mathrm{~s}$. time. 
After electropolymerization, the ITO electrodes were washed in acetonitrile in order to remove traces of the monomers and the conducting salt present on the deposited films. After drying, $\mathbf{P}_{5} \mathbf{W}_{\mathbf{3 0}}$ was incorporated by metathesis which involved dipping the modified electrode in a $0.1 \mathrm{mmol} \mathrm{L}{ }^{-1}$ aqueous $\mathrm{K}_{12.5} \mathrm{Na}_{1.5}\left[\mathrm{NaP}_{5} \mathrm{~W}_{30} \mathrm{O}_{110}\right]$ solution. The resulting poly-ZnOEP/P5W 30 hybrid film was then washed with Millipore Q water and dried. The effect of soaking time has been assessed upon recording the UV-visible abs. spectra of a series of poly-ZnOEP/P5W30 obtained after dipping the ITO electrodes for 10 to 180 minutes into the $\mathrm{K}_{12.5} \mathrm{Na}_{1.5}\left[\mathrm{NaP}_{5} \mathrm{~W}_{30} \mathrm{O}_{110}\right]$ solution. Both copolymers show a slight redshift of the Soret band showing the partial exchange of $\mathrm{PF}_{6}^{-}$by $\left[\mathrm{NaP}_{5} \mathrm{~W}_{30} \mathrm{O}_{110}\right]^{14-}$ (Fig. 7). Such behavior has been observed in the case of formation of hybrid system between porphyrin and POMs showing strong interactions between the two subunits. It can be explained by the close contact as well as the overlapping of orbitals between porphyrin and POMs. ${ }^{11}$

\subsubsection{QCM to monitor $\left[\mathrm{NaP}_{5} \mathrm{~W}_{30} \mathrm{O}_{110}\right]^{14-} / \mathrm{PF}_{6}$ exchange}

The kinetics of incorporation of $\left[\mathrm{NaP}_{5} \mathrm{~W}_{30} \mathrm{O}_{110}\right]^{14-}$ into poly-ZnOEP1 and poly-ZnOEP2 was estimated by in-situ QCM measurements using QCM electrodes covered with either poly-ZnOEP1 or poly-ZnOEP2 films in contact with the $\mathrm{K}_{12.5} \mathrm{Na}_{1.5}\left[\mathrm{NaP}_{5} \mathrm{~W}_{30} \mathrm{O}_{110}\right]$ aqueous solution. The frequency change was measured as a function of the soaking time. The frequency response associated to the insertion of $\left[\mathrm{NaP}_{5} \mathrm{~W}_{30} \mathrm{O}_{110}\right]^{14-}$ within a poly-ZnOEP1 film (obtained at applied potential: $+1.9 \mathrm{~V} v s$. SCE during $180 \mathrm{~s}$ ) is depicted in Figure 8 . The mass change due to the $\left[\mathrm{NaP}_{5} \mathrm{~W}_{30} \mathrm{O}_{110}\right]^{14-} / \mathrm{PF}_{6}{ }^{-}$exchange in the film during the one, two and three hours soaking in the $\mathrm{K}_{12.5} \mathrm{Na}_{1.5}\left[\mathrm{NaP}_{5} \mathrm{~W}_{30} \mathrm{O}_{110}\right]$ aqueous solution could be estimated after rinsing the film with ultrapure water to remove weakly adsorbed species.

Three parameters could be evaluated from this plot: $\Delta \mathrm{f}_{1}, \Delta \mathrm{f}_{2}$ and $\Delta \mathrm{f}_{3}$ which corresponded to the variation of frequency induced by $\left[\mathrm{NaP}_{5} \mathrm{~W}_{30} \mathrm{O}_{110}\right]^{14-} / \mathrm{PF}_{6}{ }^{-}$exchange in the film during the one, two and three hours soaking in the $\mathrm{K}_{12.5} \mathrm{Na}_{1.5}\left[\mathrm{NaP}_{5} \mathrm{~W}_{30} \mathrm{O}_{110}\right]$ aqueous solution in the case of poly-ZnOEP1 film. 
A decrease of the frequency value corresponds to an increase of the mass at the sensing area. The mass changes after one hour, two hours, and three hours of soaking of poly-ZnOEP1 film have been estimated to be $0.618 \mu \mathrm{g} \mathrm{cm}^{-2}, 0.912 \mu \mathrm{g} \mathrm{cm}^{-2}$ and $1.101 \mu \mathrm{g} \mathrm{cm}^{-2}$, respectively. However, after two hours (2 successive soaking cycles of 60 minutes), we observed the decrease of the frequency also during the rinsing using water showing that one part of the mass change probably came also from $\mathrm{H}_{2} \mathrm{O}$ which adsorbed also on the surface of poly-ZnOEP1/P5W30 hybrid film. This variation of the frequency allows us to calculate the mass of water which is adsorbed. For poly-ZnOEP1/P5 $\mathbf{W}_{30}$ hybrid film the mass change due to the $\left[\mathrm{NaP}_{5} \mathrm{~W}_{30} \mathrm{O}_{110}\right]^{14-}$ incorporated on the surface of poly-ZnOEP1 film calculated (Fig. 8) were $0.618 \mu \mathrm{g} \mathrm{cm}^{-2}, 0.912 \mu \mathrm{g} \mathrm{cm}^{-2}$ and $0.990 \mu \mathrm{g} \mathrm{cm}^{-2}$ after the soaking time of one hour, two hours, and three hours, respectively. The quantity of adsorbed water can also be calculated from the frequency response of QCM sensor when rinsing with water $\left(\Delta \mathrm{f}_{\mathrm{H}_{2} \mathrm{O}}\right)$ and is estimated to be $0.111 \mu \mathrm{g} \mathrm{cm}^{-2}$ after 3 hours ( 3 successive soaking cycles of 60 minutes).

The frequency response of an ITO AT-cut quartz crystal resonator modified with poly-ZnOEP2 (deposited at applied potential of $+1.9 \mathrm{~V}$ during $180 \mathrm{~s}$ ) recorded during the exchange of $\mathrm{PF}_{6}{ }^{-}$by $\left[\mathrm{NaP}_{5} \mathrm{~W}_{30} \mathrm{O}_{110}\right]^{14-}$ is shown in the ESI section (Fig. S7). The incorporation of $\left[\mathrm{NaP}_{5} \mathrm{~W}_{30} \mathrm{O}_{110}\right]^{14-}$ is found to proceed faster in poly-ZnOEP2 than in poly-ZnOEP1, most probably due to the larger charge density of poly-ZnOEP2. The effect of water adsorption was also found to be larger for poly-ZnOEP2 than for poly-ZnOEP1.

In the case of poly-ZnOEP1, because the copolymer present two time lower charges in comparison of poly-ZnOEP2 $\left(-\mathrm{py}^{+}-\mathrm{py}^{+}-2 \mathrm{PF}_{6}^{-}\right.$for poly-ZnOEP1 vs. $-\mathrm{py}^{+}-\mathrm{py}^{+}-\left(\mathrm{CH}_{2}\right)_{3}-\mathrm{py}^{+}-\mathrm{py}^{+}-4 \mathrm{PF}_{6}^{-}$for polyZnOEP2). The maximum of adsorption of of $\mathbf{P}_{5} \mathbf{W}_{\mathbf{3}}$ need more time, around 3 hours (Fig. 7B).

The molar ratio between [ZnOEP] and $\left[\mathbf{P}_{5} \mathbf{W}_{30}\right]$ in the poly-ZnOEP1/P5 $\mathbf{W}_{30}$ and polyZnOEP2/P5 $\mathbf{W}_{30}$ films has been calculated from the EQCM and QCM data. The molar ratio [ZnOEP]/[P5 $\left.\mathbf{W}_{30}\right]$ could be estimated after one hour to be 37.5 for poly-ZnOEP1/P5 $\mathbf{W} 3$ and 32.9 for poly-ZnOEP2/P5 $W_{30}$. These values are then found to decrease with time to reach 21.1 and 20.8 after three hours (Table S1). These results confirm the partial exchange of $\mathrm{PF}_{6}^{-}$by $\left[\mathrm{NaP}_{5} \mathrm{~W}_{30} \mathrm{O}_{110}\right]^{14-}$ as well as hydration of the film. 

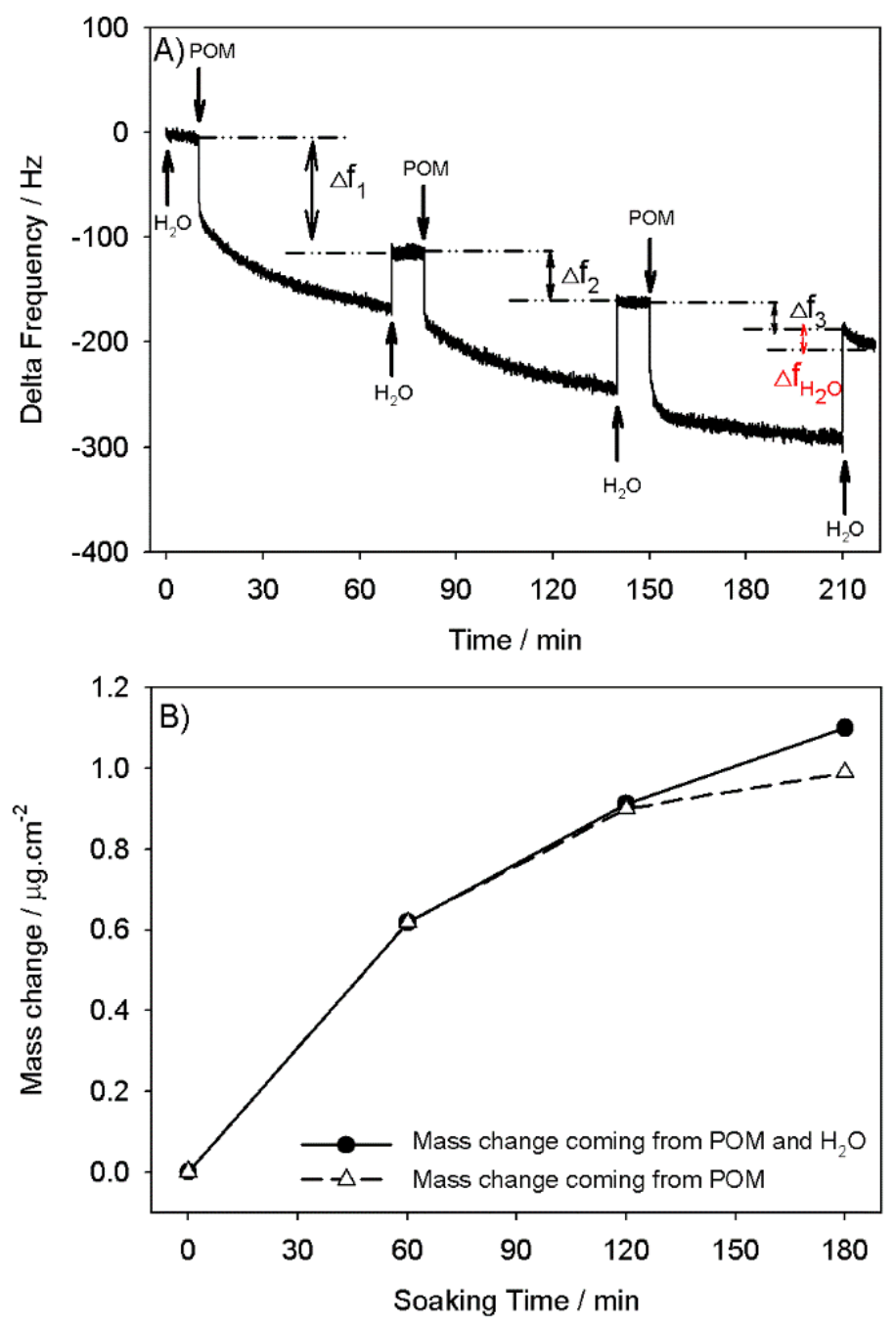

Fig. 8. Frequency response of QCM sensor to $\mathrm{K}_{12.5} \mathrm{Na}_{1.5}\left[\mathrm{NaP}_{5} \mathrm{~W}_{30} \mathrm{O}_{110}\right]$ adsorption onto the polyZnOEP1 film (deposited onto a 9.08 MHz AT-cut quartz resonator with a thin ITO layer $(\mathrm{A}=0.2$ $\left.\mathrm{cm}^{2}\right)$ ). The start base line was obtained when the sensor was exposed to $\mathrm{H}_{2} \mathrm{O}$. The arrows $\downarrow$ indicated the injection of $\mathrm{K}_{12.5} \mathrm{Na}_{1.5}\left[\mathrm{NaP}_{5} \mathrm{~W}_{30} \mathrm{O}_{110}\right]\left(\mathrm{c}=0.1 \mathrm{mmol} . \mathrm{L}^{-1}\right)$. The arrow $\uparrow$ indicated the washing using $\mathrm{H}_{2} \mathrm{O}$. B) Mass change $(\Delta \mathrm{m})$ calculated from Sauerbrey's equation versus the soaking time. $\Delta \mathrm{f}_{1}, \Delta \mathrm{f}_{2}$, and $\Delta \mathrm{f}_{3}$ are measured each time after 60 minutes (variation of frequency induced by $\left[\mathrm{NaP}_{5} \mathrm{~W}_{30} \mathrm{O}_{110}\right]^{14-}$ $/ \mathrm{PF}_{6}{ }^{-}$exchange in the film during each 60 minutes soaking cycle in the $\mathrm{K}_{12.5} \mathrm{Na}_{1.5}\left[\mathrm{NaP}_{5} \mathrm{~W}_{30} \mathrm{O}_{110}\right]$ aqueous solution; see Figure 8).

\subsubsection{Cyclic Voltammetric investigations of the hybrid films poly-ZnOEP/P $\mathrm{W}_{3} \mathrm{~W}_{3}$}

The effect of the counteranions $\left(\mathrm{PF}_{6}^{-}\right.$or $\left.\left[\mathrm{NaP}_{5} \mathrm{~W}_{30} \mathrm{O}_{110}\right]^{14-}\right)$ on the electrochemical signature of polyZnOEP was assessed upon dipping for 1 hour the ITO electrodes coated with either poly-ZnOEP1 or 
poly-ZnOEP2 in an aqueous solution of $\mathrm{K}_{12.5} \mathrm{Na}_{1.5}\left[\mathrm{NaP}_{5} \mathrm{~W}_{30} \mathrm{O}_{110}\right]\left(10^{-4} \mathrm{~mol}^{-\mathrm{L}^{-1}}\right)$ followed by washing with water $(10 \mathrm{~mL})$. The corresponding electrochemical data are collected in Table 2.

One key finding is that the CV of poly-ZnOEP1/P5W30 (Fig. S8A and Fig. S9A) and polyZnOEP2/P5W30 (Fig. S8B and Fig. S9B) recorded in acetonitrile (0.1 mol.L-1 TBAPF $\left._{6}\right)$ are similar to those recorded in the same conditions for poly-ZnOEP1 and poly-ZnOEP2, which supports the conclusion that the exchange of $\mathrm{PF}_{6}{ }^{-}$by $\left[\mathrm{NaP}_{5} \mathrm{~W}_{30} \mathrm{O}_{110}\right]^{14-}$ only occurs at the surface.

Another interesting point is that the reduction of $\mathbf{P}_{5} \mathbf{W}_{30}$ in solution, $\mathrm{TBA}_{14}\left[\mathrm{NaP}_{5} \mathrm{~W}_{30} \mathrm{O}_{110}\right]$ shows three successive reduction processes in acetonitrile system (Fig. S10). Thus, the reduction processes associated to $\left[\mathrm{NaP}_{5} \mathrm{~W}_{30} \mathrm{O}_{110}\right]^{14-}$ were not detected in the case of poly-ZnOEP1/P5 $\mathbf{W}_{30}$ or polyZnOEP2/P5W30. This behavior may also be explained by the kinetic of the electron transfer through the film between the $\mathbf{P}_{\mathbf{5}} \mathbf{W}_{\mathbf{3 0}}$ and the porphyrin subunits which might be drastically slowed down. Such behavior has been already reported, even in solution, with various POMs-porphyrin systems. ${ }^{\mathbf{1 1 b}, \mathbf{e}, \mathbf{1 3 , 2 1}}$

To understand the photocurrent generation, it is also of interest to look at the current potential curves obtained in acetonitrile using $\mathrm{Na}^{+} \mathrm{I}^{-}$as electrolyte instead of 0.1 mol.L ${ }^{-1} \mathrm{TBAPF}_{6}$ (Fig. 9).

We found that the presence of $\mathrm{I}^{-}$in the electrolyte leads to a significant cathodic shift of the waves corresponding to the reduction of the viologen units, which reflects the importance of the ion-pairing effects in organic media.

Note however, that in the anodic region, the oxidation current of $\mathrm{I}^{-}$is masking the oxidation peak of porphyrin because of the large excess of $\mathrm{I}^{-}\left(0.5 \mathrm{~mol} . \mathrm{L}^{-1}\right)$ present in solution. In addition, the oxidation potential of the porphyrin unit remains nearly unchanged using various type of electrolyte. Thus, measurement of the first oxidation potential of ZnOEP subunit of poly-ZnOEP1/P5W30 (Fig. 9A, Fig. S11A and Fig. S12A) and poly-ZnOEP2/P5W30 are carried out in acetonitrile containing 0.1 mol.L $\mathrm{L}^{-1}$ TBAPF $_{6}$ (Fig. S11B, Fig. S12B and Fig. S13).

The current potential curves of poly-ZnOEP1/P5 $\mathbf{W}_{30}$ were also measured in aqueous solution containing $\mathrm{NaI}\left(0.1 \mathrm{~mol} . \mathrm{L}^{-1}\right)$. As in acetonitrile, three reduction waves due to the reduction of the viologen spacers were observed at slightly higher potential than in acetonitrile (Fig. 9B and Table 2). 

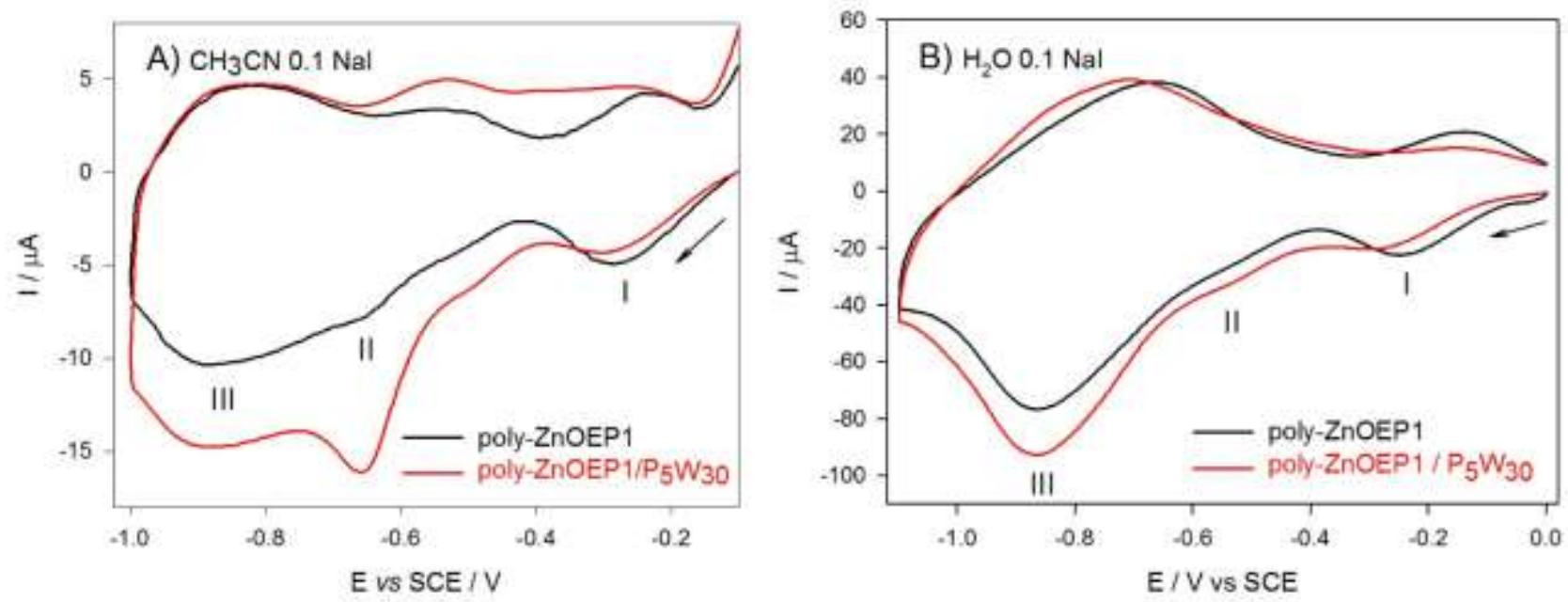

Fig. 9. CVs of poly-ZnOEP1 (black line) and poly-ZnOEP1/P5 $\mathbf{W}_{30}$ (red line) films on ITO in A) acetonitrile and B) $\mathrm{H}_{2} \mathrm{O}$ containing 0.5 mol. $\mathrm{L}^{-1} \mathrm{NaI} . \mathrm{S}=1 \mathrm{~cm}^{2} . v=20 \mathrm{mV} \mathrm{s}^{-1} .(\rightarrow)$ shows the scan direction.

\subsubsection{X-ray photoelectron spectra (XPS) of poly-ZnOEP/P ${ }_{5} W_{30}$.}

XPS analyses have been carried out to confirm the presence of the $\left[\mathrm{NaP}_{5} \mathrm{~W}_{30} \mathrm{O}_{110}\right]^{14-}$ polyoxometalate on the surface of the films. The presence of Na 1s (1073.4 eV, Fig. 6, red curve) and W 4f7 (36.4 eV for $\mathrm{W} 4 \mathrm{f} 7 / 2$ and $37.8 \mathrm{eV}$ for W4f5/2, Fig. $6 \mathrm{H}$, red curve) peaks, the much lower intensity of $\mathrm{F} 1 \mathrm{~s}$ (686.8 eV, Fig. 6I, red curve), together with the signal of O 1s (531.6 eV, Fig. 6D, red curve) and P 2p3 (133.3 eV, Fig. 6E, red curve) arising from the $\mathrm{P}-\mathrm{O}$ bonds in $\mathrm{POM}$ species further support the conclusion that $\left[\mathrm{NaP}_{5} \mathrm{~W}_{30} \mathrm{O}_{110}\right]^{14-}$ species are adsorbed on the poly-ZnOEP1 film to yield poly-ZnOEP1/P5 $\mathbf{W}_{30}$. XPS data collected with poly-ZnOEP2 and poly-ZnOEP2/P5W30 (Fig. S4) are analogous to those recorded with poly-ZnOEP1 and poly-ZnOEP1/P5W30. The P $2 p$ line at binding energy of $136.6 \mathrm{eV}$ for polyZnOEP1 (136.7 eV for poly-ZnOEP2) as well as the F 1s line at $686 \mathrm{eV}$ are attributed to the $\mathrm{PF}_{6}$ counteranions $^{22}$ while the signal of $\mathrm{P} 2 \mathrm{p}$ at $133.3 \mathrm{eV}$ corresponds to the binding energy of the five phosphorus atoms in $\left[\mathrm{NaP}_{5} \mathrm{~W}_{30} \mathrm{O}_{110}\right]^{14-}$. It confirms the exchange of $\mathrm{PF}_{6}^{-}$by $\left[\mathrm{NaP}_{5} \mathrm{~W}_{30} \mathrm{O}_{110}\right]^{14-}$. Similar behaviors have been observed for poly-ZnOEP2 and poly-ZnOEP2/P5W30.

\subsubsection{Film Morphology (Atomic Force Microscopy)}


AFM analyses conducted on both polymers poly-ZnOEP1/P5 $\mathbf{W}_{30}$ and poly-ZnOEP2/P5 $\mathbf{W}_{30}$ led to similar topographic images with rms surface roughness ranging from $2.2 \mathrm{~nm}$ for poly-ZnOEP1/P5 $\mathbf{W}_{30}$ to $2.0 \mathrm{~nm}$ for poly-ZnOEP2/P5W30 (Fig. 10). The deposited copolymers appear on the surface as tightly packed coils with an average diameter of ca. 70-100 nm.
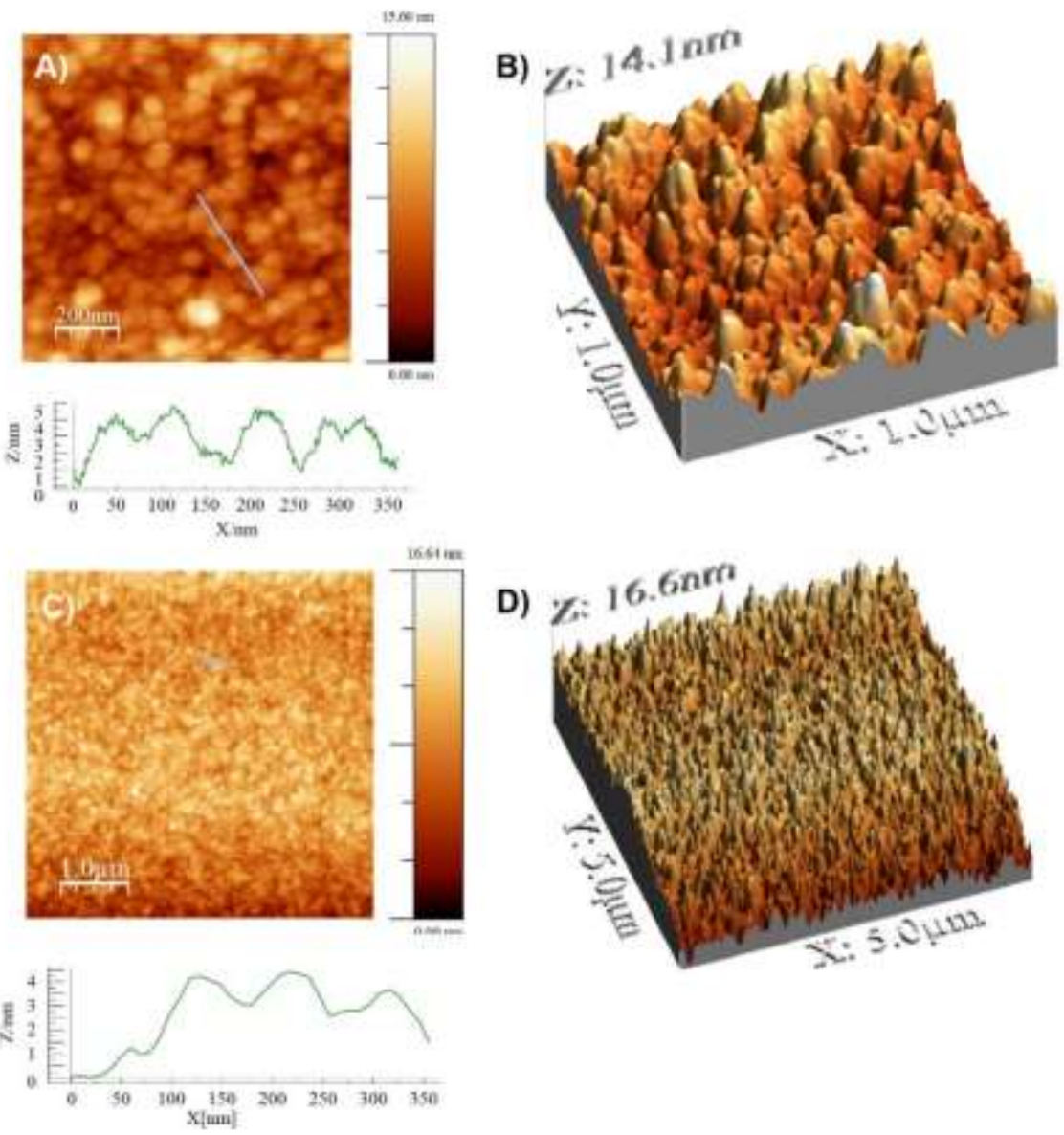

Fig. 10. Tapping mode AFM topography of A) and B) poly-ZnOEP1/P5W30 and C) and D) polyZnOEP2/P5 $\mathbf{W}_{30}$ hybrid films and section analysis of the aggregate marked by a blue lines.

\subsection{Photoelectrochemical properties}

The photoelectrochemical properties of the poly-ZnOEP1 and poly-ZnOEP2 hybrids films (e.g. the photocurrent generation and the photovoltage under open circuit conditions) have been investigated both in acetonitrile and in aqueous solutions containing $\mathrm{I}_{3}^{-} 5 \mathrm{mmol} \mathrm{L}^{-1}$ and $\mathrm{I}^{-} 0.5 \mathrm{~mol} \mathrm{~L}^{-1}$ as redox 
mediators. Sodium iodide also acts as a supporting electrolyte ensuring a good conductivity of the medium.

\subsubsection{Influence of the solvent}

Figure 11 shows the photocurrent response of poly-ZnOEP1 and poly-ZnOEP2 hybrid films obtained in acetonitrile and in aqueous solutions. In the absence of POM, the poly-ZnOEP1 and poly-ZnOEP2 films were found to exhibit a positive photocurrent involving the oxidation of $\mathrm{I}^{-}$in acetonitrile (Figures 11A and 11C). The photocurrent response was moreover found to be prompt, steady and reproducible even after four hours off on-off cycles involving irradiation with a Xenon lamp.

Light Irradiation was also found to induce a cathodic shift of the open circuit potential values measured for poly-ZnOEP1 and poly-ZnOEP2 on ITO electrodes (Table S3). The energy diagram corresponding to the photooxidation of $\mathrm{I}^{-}$will be discussed in more details later in Figure $14 \mathrm{~A}$. Briefly, after absorption of a photon, an electron transfer occurs from the excited ZnOEP to the viologen spacer and then to the ITO.

The oxidized $\mathbf{Z n O E P}$ can then in turn be reduced by $\mathrm{I}^{-}$, while $\mathrm{I}_{3}^{-}$is reduced at the platinum counter electrode.

Interestingly, the signs of the photocurrent at $0.0 \mathrm{~V}$ bias potential and of the photovoltage are inverted when the same modified electrodes are used (poly-ZnOEP1 and poly-ZnOEP2), in aqueous solution (Fig. 11B and Table S3). This reveals an inversion of the electron transfer direction under illumination in aqueous solution according to the energy level diagrams displayed in Figure 14B. The origin of this inversion is still unclear at the present stage, it might be tentatively attributed to the influence of the solvent on the electron transfer kinetics between the poly-ZnOEP and the ITO electrode (see the EIS results below).

\subsubsection{Influence of the type of spacer}

In the absence of POM, the best photoelectrochemical performances have been obtained with polyZnOEP2 featuring a bis-viologen spacer. In acetonitrile, the photocurrent measured at $0.0 \mathrm{~V}$ bias 
potential vs. the Pt counter electrode and the photovoltage measured under open circuit conditions have been found to be significantly better for poly-ZnOEP2 (ca. $16 \mu \mathrm{A} . \mathrm{cm}^{-2}$ and $-73 \mathrm{mV}$ ) than for polyZnOEP1 of (ca. $9 \mu \mathrm{A} . \mathrm{cm}^{-2}$ and $-20 \mathrm{mV}$ ) (Table S3). This suggests that the presence of a bis-viologen spacer is beneficial for the charge separation in the polymer film. The positive role of the bis-viologen spacer is also confirmed by measurements carried out in aqueous solution, where a photocurrent as high as $-80 \mu \mathrm{A} . \mathrm{cm}^{-2}$ could be obtained with poly-ZnOEP2 (compared to ca. $-6 \mu \mathrm{A} . \mathrm{cm}^{-2}$ for the polyZnOEP1 polymer).

\subsubsection{Optimization of the soaking time in $\mathrm{K}_{12.5} \mathrm{Na}_{1.5}\left[\mathrm{NaP}_{5} \mathrm{~W}_{30} \mathrm{O}_{110}\right]$ solution}

The influence of the POM on the photoelectrochemical properties of the poly-ZnOEP1 and polyZnOEP2 hybrids films has been studied both in acetonitrile and in water. Figures 11-12 and Figures S14-S15 show the photocurrent response of poly-ZnOEP1/P5 $W_{30}$ and poly-ZnOEP2/P5 $\mathbf{W}_{30}$ hybrid films respectively obtained under Xe irradiation $(\lambda>385 \mathrm{~nm})$ by soaking in a $\mathrm{K}_{12.5} \mathrm{Na}_{1.5}\left[\mathrm{NaP}_{5} \mathrm{~W}_{30} \mathrm{O}_{110}\right]$ solution for fixed durations. In these conditions, $\mathrm{K}_{12.5} \mathrm{Na}_{1.5}\left[\mathrm{NaP}_{5} \mathrm{~W}_{30} \mathrm{O}_{110}\right]$ is not expected to be excited.

The photoelectrochemical properties have been initially investigated in acetonitrile. We found that the magnitude of the photocurrent response of the poly-ZnOEP1/P5 $\mathbf{W}_{30}$ and poly-ZnOEP2/P5 $\mathbf{W}_{30}$ films is significantly increased in the presence of the polyoxometalate $\mathbf{P}_{5} \mathbf{W}_{\mathbf{3 0}}$. At $0.00 \mathrm{~V}$ bias potential, the photocurrent was found to be 3.4 times larger for poly-ZnOEP1/P5 $\mathbf{W}_{30}\left(60 \mathrm{~min}\right.$. soaking in $\mathrm{P}_{5} \mathrm{~W}_{30}$ solution) than for poly-ZnOEP1 and 1.3 times larger for poly-ZnOEP2/P5 $\mathbf{W}_{30}$ (30 min. soaking in $\mathbf{P}_{5} \mathbf{W}_{30}$ solution) than for poly-ZnOEP2. The comparison is done using the soaking time giving the maximum of magnitude of the photocurrent (60 minutes for poly-ZnOEP1/P5 $\mathbf{5} 30$ versus 30 minutes. for poly-ZnOEP2/P5 $\mathbf{3} 3$, Fig. 12, Fig. S14 and Fig. S15). The corresponding photocurrent measured were 31.89 for poly-ZnOEP1/P5 $\mathbf{W}_{30}$ and $24.90 \mu \mathrm{A} / \mathrm{cm}^{2}$ for poly-ZnOEP2/P5 $\mathbf{3}$ 30. The incorporation of POMs also leads to an improvement of the photovoltage up to $-28 \mathrm{mV}$ and $-105 \mathrm{mV}$ for polyZnOEP1/P5W 30 and poly-ZnOEP2/P5W30, respectively. 

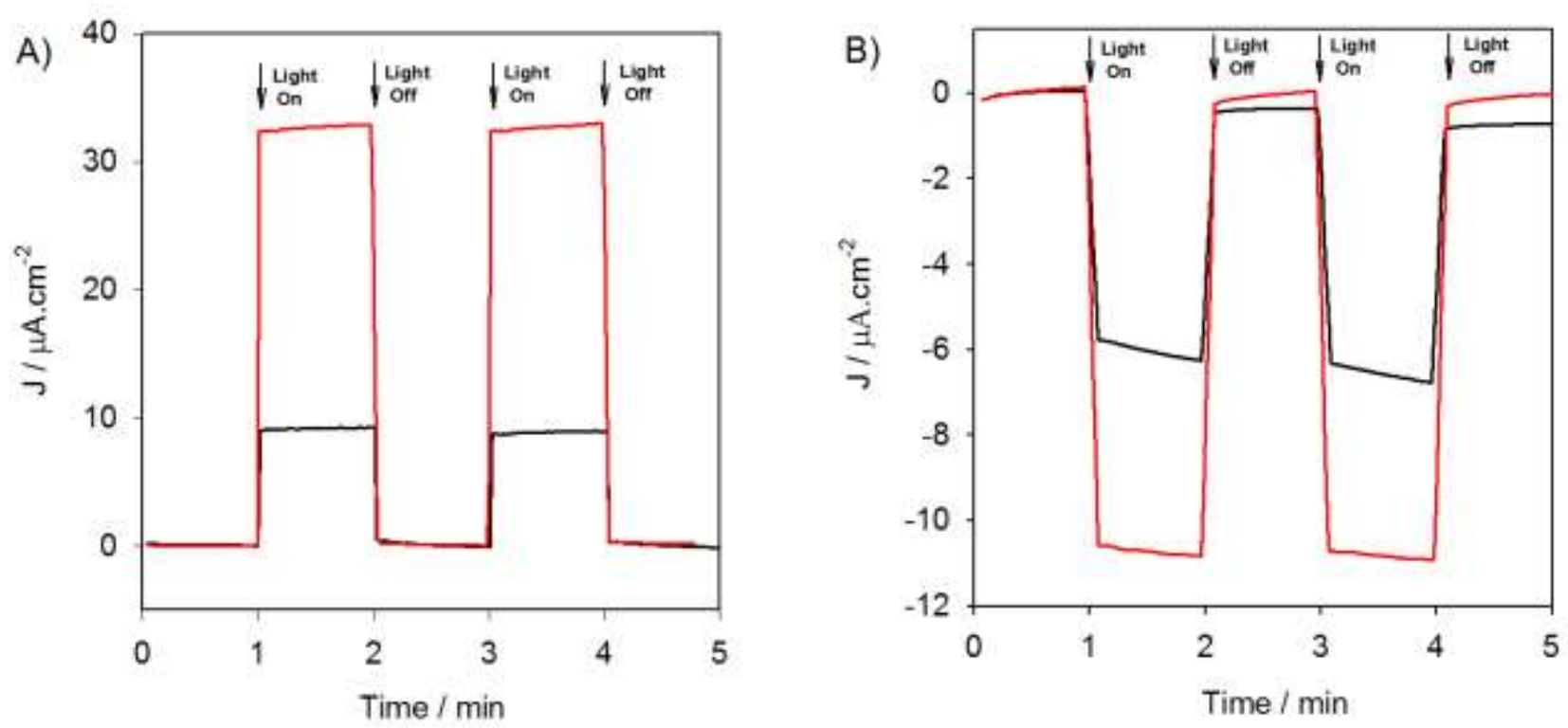

Fig. 11. Photoelectrochemical response of poly-ZnOEP1 (black line) and poly-ZnOEP1/P5 $W_{30}$ (red line) (soaking time in $\mathrm{P}_{5} \mathrm{~W}_{30}$ solution with 60 min) A) in acetonitrile and $\mathrm{B}$ ) in $\mathrm{H}_{2} \mathrm{O}$ under on-off light illumination from a $300 \mathrm{~W}$ Xe arc lamp (with $\lambda>385 \mathrm{~nm}$ long pass filter) in containing $\mathrm{I}_{3}^{-} 5 \mathrm{mmol.L}^{-}$ ${ }^{1}$ and $\mathrm{I}^{-} 0.5$ mol. $\mathrm{L}^{-1}$. BIAS potential: $0.00 \mathrm{~V} v s$. OCP.

Based on the energy levels of the various components (ZnOEP, P5W $\mathbf{3 0}$, viologen (or bis-viologen) and $\mathrm{I}_{3}{ }^{-} / \mathrm{I}^{-}$) displayed in Figure 14A, the $\mathbf{P}_{\mathbf{5}} \mathbf{W}_{\mathbf{3 0}}$ can act as an efficient mediator promoting the electron transfer from the excited ZnOEP to the viologen (or bis-viologen) acceptor and enhancing the electron-hole pairs separation in the poly-ZnOEP.

Similar experiments carried out in water led to less clear-cut conclusions. The magnitude of the photocurrent of poly-ZnOEP1/P5 $\mathbf{3} 30$ was enhanced by a factor of two after soaking for 60 minutes in P5W30 solution (Fig. 11B, Fig. 12 and Fig. S15A), but a significant decrease of the polyZnOEP2/P5W30 photocurrent by a factor four could be observed (Fig. S14B and Fig. S15B). This decrease can be tentatively attributed to a modification of the structure of the polymer film in the presence of the POM, resulting in a less efficient charge transfer between the ITO electrode and the film. 

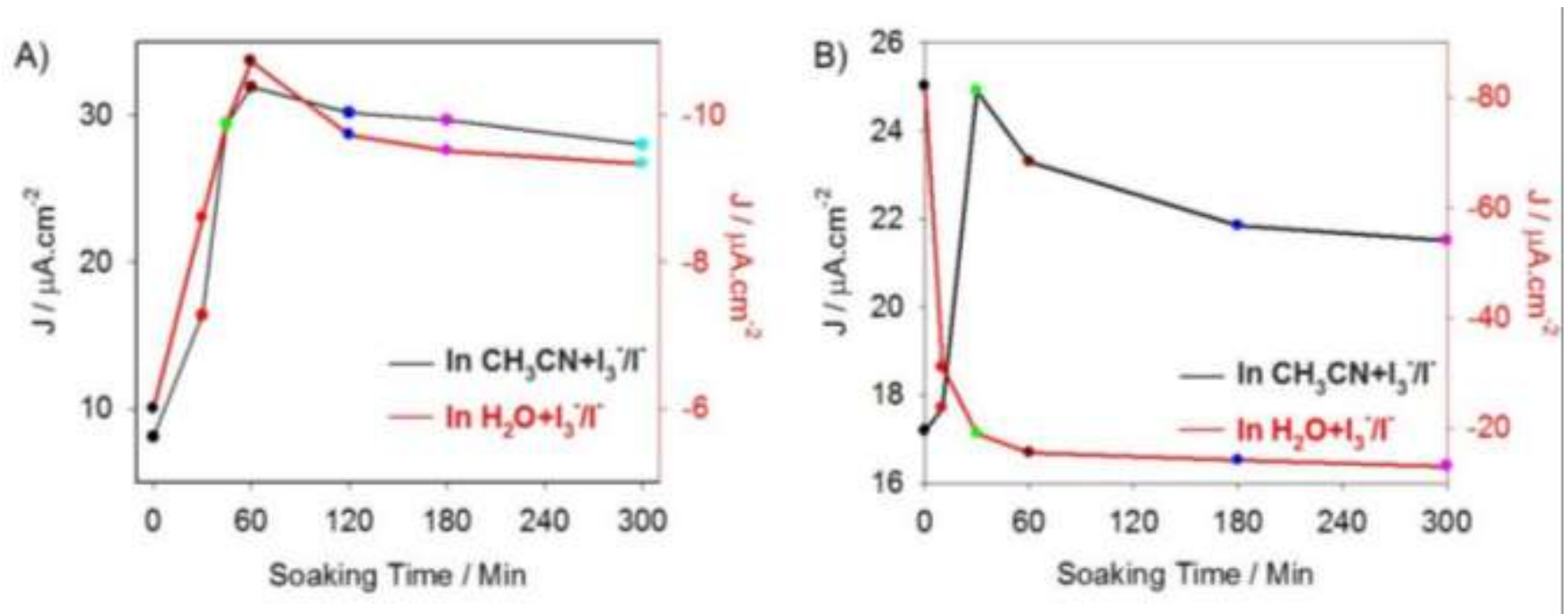

Fig. 12. Photoelectrochemical response of A) poly-ZnOEP1/P5W30 and poly-ZnOEP2/P5W30 with different soaking time in $\mathrm{K}_{12.5} \mathrm{Na}_{1.5}\left[\mathrm{NaP}_{5} \mathrm{~W}_{30} \mathrm{O}_{110}\right]$ solution under on-off light illumination from a 300 W Xe arc lamp (with $\lambda>385 \mathrm{~nm}$ long pass filter) in acetonitrile (black line) and $\mathrm{H}_{2} \mathrm{O}$ (red line) containing $\mathrm{I}_{3}^{-} 5$ mmol. $\mathrm{L}^{-1}$ and $\mathrm{I}^{-} 0.5$ mol.L $\mathrm{L}^{-1}$. BIAS potential: $0.00 \mathrm{~V} v s$. OCP.

\subsubsection{Electrochemical impedance spectroscopic analysis}

Electrochemical impedance spectroscopy (EIS) has been widely used to investigate the kinetics of electronic or ionic processes in dye-sensitized solar cells. ${ }^{23}$ By analyzing the current response to a small amplitude potential perturbation from the steady state, the charge transfer resistance $R_{c t}$ associated to the electron transfer at the electrode/electrolyte interface as well as the parameters of the charge transport in the porous electrode and of the recombination reaction can be extracted. In the present work, EIS measurements have been carried out in aqueous and in acetonitrile solutions containing $\mathrm{I}_{3}^{-}\left(5 \mathrm{mmol} . \mathrm{L}^{-1}\right)$ and $\mathrm{I}^{-}\left(0.5 \mathrm{~mol} . \mathrm{L}^{-1}\right)$ in order to get further insights into the rate and efficiency of the electron transfer processes. The experimental data could be fitted within good approximation using the equivalent circuit displayed in Figure 13C. The Nyquist plots obtained for poly-ZnOEP1/P5 $\mathbf{W}_{30}$ with and without illumination at a bias potential of $0.0 \mathrm{~V}$ in acetonitrile and in water are displayed in Figure 13 and the curve fitting data obtained with poly-ZnOEP1/P5 $\mathbf{W}_{30}$ are summarized in the Table 3. Two semicircles are observed in the Nyquist plot of poly-ZnOEP1/P5 $\mathbf{3} 3 \mathbf{3 0}$ in acetonitrile. The first low resistance (from 300 to $430 \Omega$ ) and high frequency arc is attributed to the 
charge transfer processes at the ITO/poly-ZnOEP1/P5 $\mathbf{W}_{30}$ interface modeled by the parallel

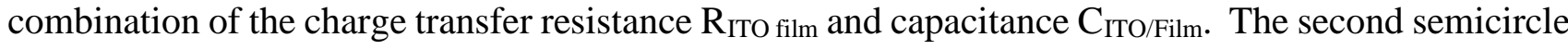
with higher resistance (from 780 to $1440 \Omega$ ) at lower frequency is mainly assigned to the charge transfer process between poly-ZnOEP1/P5 $\mathbf{W}_{30}$ and the $\mathrm{I}_{3}{ }^{-} / \mathrm{I}^{-}$species in the electrolyte; it results from the coupling of the chemical capacitance of the polymer film $\mathrm{C}_{\text {film }}$ in parallel with the charge transfer resistance of the film to the redox species in the electrolyte $R_{c t}$ film. In contrast, the Nyquist diagrams obtained in aqueous solution (Figure 13B) feature only one semi-circle with a much higher value of the charge transfer resistances (from 19 to $130 \mathrm{k} \Omega$ ) than the ones measured in acetonitrile and that can be assigned to the electron transfer at the ITO/poly-ZnOEP1/P5W 30 interface. The origin of the huge increase of $\mathrm{R}_{\mathrm{ITO} / \mathrm{Film}}$ in aqueous solution might be tentatively attributed to a modification of the structure of the polymer film induced by the solvent. Also, it should be noticed that the much larger value of $\mathrm{R}_{\mathrm{ITO} / \mathrm{Film}}$ compared to $\mathrm{R}_{\mathrm{ct}}$ film (Table 3) might be one of the reasons for the inversion of the direction of the electron transfer observed in aqueous solution. Obviously, the low frequency part of the impedance spectra obtained in aqueous solution without illumination cannot be fully reproduced by the fit using the equivalent circuit displayed in Figure $13 \mathrm{C}$, revealing that the charge transfer in the electrochemical system is affected by another process below $0.1 \mathrm{~Hz}$.

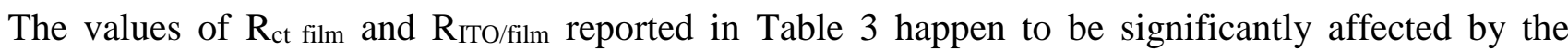
illumination, as revealed by the significant decrease of the diameter of the arcs observed under illumination. The drop in the charge transfer resistance value $\mathrm{R}_{\text {ITO film observed both in aqueous }}$ solution and in acetonitrile might be attributed to a local increase of the temperature due to the illumination which accelerates the electron transfer kinetic between the ITO and the copolymer. The different effect of light on the $\mathrm{R}_{\mathrm{ct}}$ film value in aqueous solution and in acetonitrile might arise from the local variation of the $\mathrm{I}_{3}{ }^{-}$concentration induced by the photocurrent generation (the local $\mathrm{I}^{-}$ concentration being approximately constant). In this case, the increase of the local concentration in $\mathrm{I}_{3}{ }^{-}$ by the anodic photocurrent in acetonitrile will tend to decrease the value of $\mathrm{R}_{\mathrm{ct}}$ film while in aqueous solution the consumption of $\mathrm{I}_{3}{ }^{-}$in the vicinity of the electrode will rather provoke an increase of $\mathrm{R}_{\mathrm{ct}}$ film as observed in Table 3 . 
A detailed analysis of the impedance spectra provides further insights on the role of the POM in the photoelectrochemical system. Clearly, the incorporation of the POM results in a significant decrease of the $\mathrm{R}_{\mathrm{ITO} / \mathrm{Film}}$ in aqueous solution and in acetonitrile, revealing that the presence of the POM accelerates the electron transfer kinetics between the ITO and the film and thus contributes to the enhancement of the photocurrent generation. It should also be mentioned that the $R_{c t}$ film value calculated in acetonitrile decreases in the presence of the POM, suggesting that in this case the kinetics of the recombination reaction with the photogenerated $\mathrm{I}_{3}{ }^{-}$might also be enhanced by the POM.

Finally, the Nyquist plots recorded for poly-ZnOEP2/P5 $\mathbf{W}_{30}$ (Figure S16) exhibit only one semi-circle in aqueous solution and in acetonitrile, making the determination of the $\mathrm{R}_{\mathrm{ITO}}$ film and $\mathrm{R}_{\mathrm{ct}}$ film values more difficult. Overall, similar trends can be observed with poly-ZnOEP1/P5W 30 and poly-ZnOEP2/P5W30 in acetonitrile.

In aqueous solution, one remarkable feature is the strong decrease of the impedance semicircle diameter of the poly-ZnOEP2 film in the presence of light which is compatible with the large photocurrent values. In this particular case, the diameter of the impedance semicircle is increased when the POM is incorporated, revealing a decrease of the electron transfer kinetics.

Table 3. Fitting results for the EIS measurements performed in $\mathrm{CH}_{3} \mathrm{CN}$ or $\mathrm{H}_{2} \mathrm{O}$.

\begin{tabular}{|c|c|c|c|c|c|c|c|c|}
\hline \multirow[b]{2}{*}{ Solvent } & \multicolumn{2}{|c|}{$\begin{array}{l}\text { ZnOEP1 } \\
\text { dark }\end{array}$} & \multicolumn{2}{|c|}{$\begin{array}{c}\text { ZnOEP1 } \\
\text { light }\end{array}$} & \multicolumn{2}{|c|}{$\begin{array}{c}\text { ZnOEP1/P5W30 } \\
\text { dark }\end{array}$} & \multicolumn{2}{|c|}{$\begin{array}{c}\mathrm{ZnOEP} / \mathbf{P}_{5} \mathbf{W}_{30} \\
\text { light }\end{array}$} \\
\hline & $\mathrm{CH}_{3} \mathrm{CN}$ & $\mathrm{H}_{2} \mathrm{O}$ & $\mathrm{CH}_{3} \mathrm{CN}$ & $\mathrm{H}_{2} \mathrm{O}$ & $\mathrm{CH}_{3} \mathrm{CN}$ & $\mathrm{H}_{2} \mathrm{O}$ & $\mathrm{CH}_{3} \mathrm{CN}$ & $\mathrm{H}_{2} \mathrm{O}$ \\
\hline $\mathrm{R}_{\text {ITO/Film }} / \Omega$ & 429 & 103140 & 395 & 48705 & 356 & 134459 & 297 & 19501 \\
\hline $\mathrm{C}_{\mathrm{ITO} / \mathrm{Film}} / \mu \mathrm{F}$ & 11 & 11 & 11 & 11 & 13 & 11 & 13 & 14 \\
\hline $\mathrm{R}_{\mathrm{ct} \_ \text {film }} / \Omega$ & 1440 & 1071 & 1072 & 1534 & 1186 & 866 & 778 & 5504 \\
\hline $\mathrm{C}_{\text {film }} / \mu \mathrm{F}$ & 106 & 199 & 107 & 119 & 113 & 247 & 127 & 317 \\
\hline
\end{tabular}



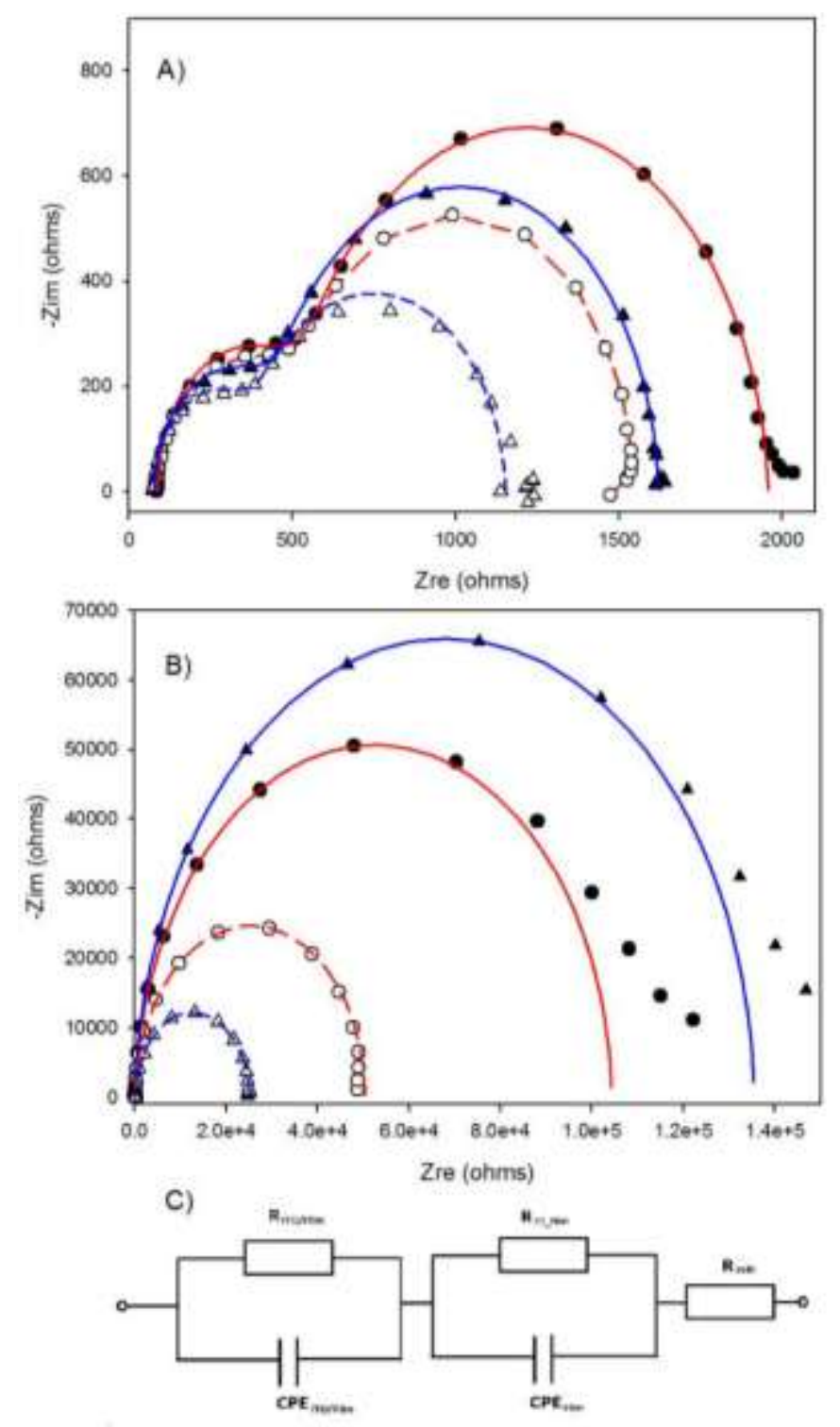

Fig. 13. Electrochemical impedance spectroscopy (EIS) for poly-ZnOEP1/P5 $\mathbf{W}_{30}$ (soaking time in $\mathrm{P}_{5} \mathrm{~W}_{30}$ solution with 60 min) in $\mathrm{A}$ ) in acetonitrile and $\mathrm{B}$ ) in $\mathrm{H}_{2} \mathrm{O}$ with and without illumination from a $300 \mathrm{~W}$ Xe arc lamp (with $\lambda>385 \mathrm{~nm}$ long pass filter) containing $\mathrm{I}_{3}^{-} 5 \mathrm{mmol} . \mathrm{L}^{-1}$ and $\mathrm{I}^{-} 0.5 \mathrm{~mol} . \mathrm{L}^{-1}$ Under illumination the BIAS potential was $0.00 \mathrm{~V} v s$. OCP. In the dark, the BIAS potential was the OCP of the same film under illumination $v s$. SCE.

\subsubsection{Energy diagram of the electron transfer processes}

The anodic photo-electric current measured with poly-ZnOEP1/P5 $\mathbf{W}_{30}$ and poly-ZnOEP2/P5W 30 film in acetonitrile involve the following processes: $i$ ) the band-gap excitation from HOMO to LUMO 
of the ZnOEP macrocycle under illumination, $i$ ) electron transfer from the LUMO of ZnOEP to $\mathbf{P}_{5} \mathbf{W}_{30}$, while $\mathrm{I}^{-}$transfer one electron to the HOMO of $\mathbf{Z n O E P}$, iii) the reduced $\mathbf{P}_{\mathbf{5}} \mathbf{W}_{\mathbf{3 0}}$ mediates the reduction of the viologen (or bis-viologen) dications, $i v$ ) viologen (or bis-viologen) cation radicals transfer the electron to ITO electrode (Fig. 14A).

The potential of the first oxidation of the $\mathbf{Z n O E P}(\mathrm{P})$ species in the film provides a direct measurement of the energy of the HOMO level. The potential of the excited porphyrin can be calculated by subtracting the excitation energy from the ground state oxidation potential of the porphyrin, which is correlated with the ability of the excited porphyrin to transfer electrons to $\mathbf{P}_{5} \mathbf{W}_{\mathbf{3 0}}$.

$$
E\left(\mathrm{P}^{+*} / \mathrm{P}^{*}\right)=E\left(\mathrm{P}^{+*} / \mathrm{P}\right)-E_{\mathrm{S} 0 \rightarrow \mathrm{S} 1}(\text { Equation } 4)
$$

From the electron affinity, the $\mathrm{E}_{\mathrm{c}}$ edges of ITO electrode surface are estimated to be ca. $-4.71 \mathrm{eV}$ and $-5.01 \mathrm{eV}$ in $\mathrm{CH}_{3} \mathrm{CN}$ and $\mathrm{H}_{2} \mathrm{O}$ containing $0.5 \mathrm{~mol} \mathrm{~L}-1 \mathrm{I}^{-}$, respectively. The level of the excited state (couple $\mathrm{P}^{+*} / \mathrm{P}^{*}$ ) and the ground state (couple $\mathrm{P}^{+*} / \mathrm{P}$ ) are $-3.92 \mathrm{eV}$ and $-5.92 \mathrm{eV}$ for poly-ZnOEP1/P5 $\mathbf{W} 3$, and $-3.90 \mathrm{eV}$ and $-5.94 \mathrm{eV}$ for poly-ZnOEP2/P5 $\mathbf{5} 3$, respectively. The energy level of the couples $\mathrm{P}_{5} \mathrm{~W}^{\mathrm{VI}}{ }_{30} / \mathrm{P}_{5} \mathrm{~W}^{\mathrm{V}} \mathrm{V}^{\mathrm{VI}} 29$ were $-4.08 \mathrm{eV}\left(-0.42 \mathrm{~V} v s\right.$. NHE) and $-4.41 \mathrm{eV}\left(-0.09 \mathrm{~V}\right.$ vs. NHE) in $\mathrm{CH}_{3} \mathrm{CN}$ and $\mathrm{H}_{2} \mathrm{O}$ containing $0.5 \mathrm{~mol} \mathrm{~L}{ }^{-1} \mathrm{I}^{-}$, respectively. The energy level of $\mathrm{V}^{2+} / \mathrm{V}^{+\bullet}$ in poly-ZnOEP1/ $\mathrm{P}_{5} \mathrm{~W}_{30}$ were $-4.41 \mathrm{eV}\left(-0.09 \mathrm{~V}\right.$ vs. NHE) and $-4.48 \mathrm{eV}\left(-0.02 \mathrm{~V}\right.$ vs. NHE) in $\mathrm{CH}_{3} \mathrm{CN}$ and $\mathrm{H}_{2} \mathrm{O}$ containing $0.5 \mathrm{~mol}$ $\mathrm{L}^{-1} \mathrm{I}^{-}$, respectively. The energy level of $\mathrm{I}_{3}{ }^{-} / \mathrm{I}^{-}$were $-4.70 \mathrm{eV}$ and $-5.06 \mathrm{eV}$ respectively, in $\mathrm{CH}_{3} \mathrm{CN}$ and $\mathrm{H}_{2} \mathrm{O}$ containing $0.5 \mathrm{~mol} \mathrm{~L}^{-1} \mathrm{I}^{-}$on the absolute scale.

In contrast, the cathodic photo-electric conversion mechanism of poly-ZnOEP1/P5 $\mathbf{W}_{30}$ and polyZnOEP2/P5W30 film observed in aqueous solution could be explained by the following processes: (1) the band-gap excitation from HOMO to LUMO of the ZnOEP macrocycle under illumination, (2) electron transfer from the LUMO of $\mathbf{Z n O E P}$ to $\mathbf{P}_{\mathbf{5}} \mathbf{W}_{\mathbf{3 0}}$, (3) the reduced $\mathbf{P}_{\mathbf{5}} \mathbf{W}_{\mathbf{3 0}}$ relay electron to viologen (or bis-viologen) dications, (4) viologen (or bis-viologen) cation radicals transfer electrons to $\mathrm{I}_{3}{ }^{-}$which is reducted into $\mathrm{I}^{-}$, (5) reoxidation of the $\mathrm{I}^{-}$at the Pt counter-electrode, the $\mathbf{Z n O E P}$ being regenerated by an electron transfer from the ITO (Fig. 14). 

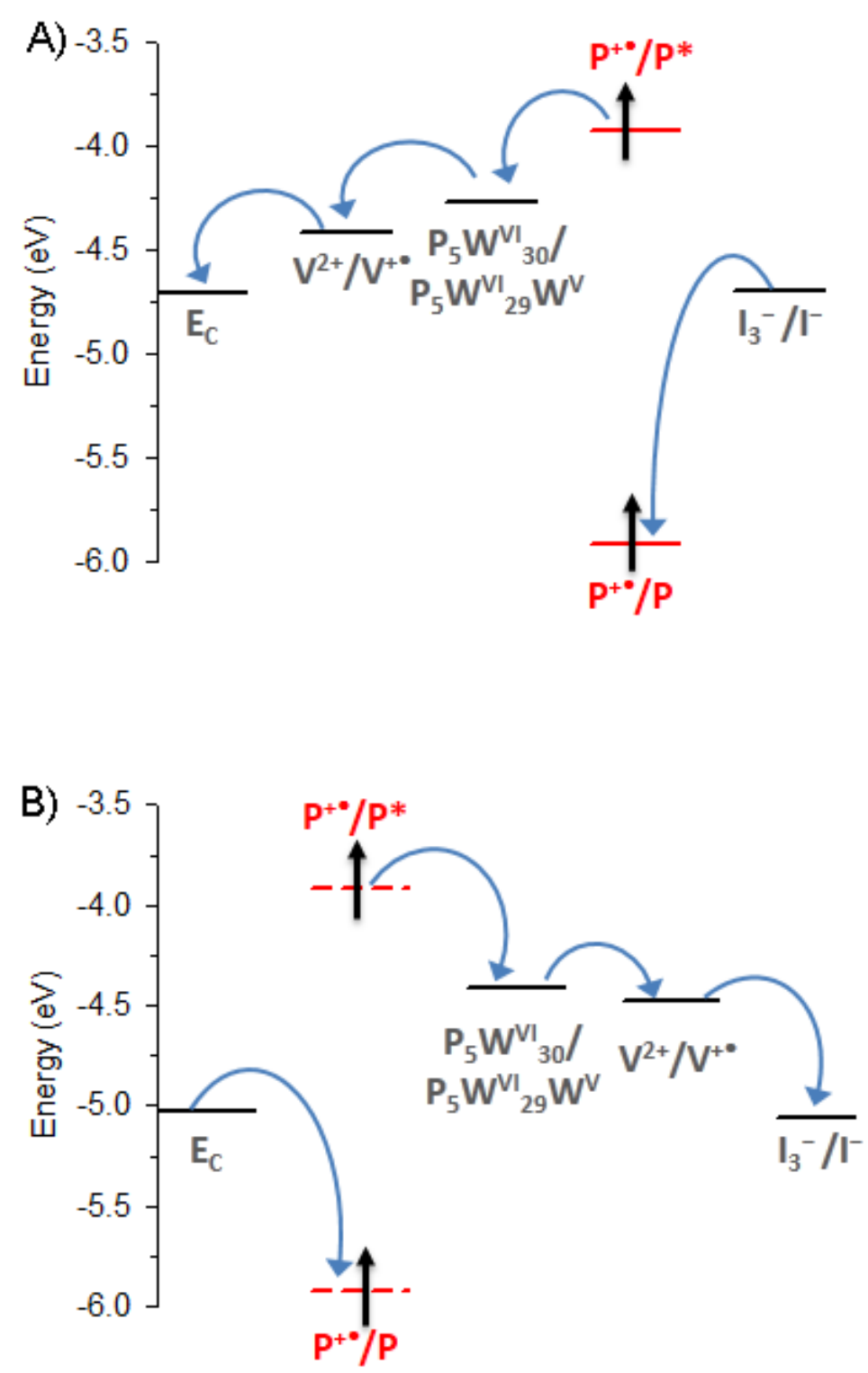

Fig. 14. Schematic illustration of the energy level diagram showing electron transfer processes of polyZnOEP1/P5 $\mathbf{P}_{30}$ in $\left.\mathrm{A}\right)$ in acetonitrile and $\left.\mathrm{B}\right)$ in $\mathrm{H}_{2} \mathrm{O}$ containing $\mathrm{I}_{3}{ }^{-} 5 \mathrm{mmol} \cdot \mathrm{L}^{-1}$ and $\mathrm{I}^{-} 0.5 \mathrm{~mol} . \mathrm{L}^{-1}$. $(\mathrm{V}=$ viologen, $\mathrm{P}=$ porphyrin).

\section{Conclusion}

In summary, two poly-ZnOEP/P5 $\mathbf{W}_{30}$ films have been prepared through the incorporation of $\left[\mathrm{NaP}_{5} \mathrm{~W}_{30} \mathrm{O}_{110}\right]^{14-}$ in poly-ZnOEP films involving either rigid/short viologen linkers or flexible/long 
bis-viologen linkers introduced between the ZnOEP macrocycles. We found that both polyZnOEP/P5 $\mathbf{W}_{30}$ composite film electrodes feature higher response than the POM-free poly-ZnOEP electrodes in acetonitrile. This can be attributed to $\mathbf{P}_{\mathbf{5}} \mathbf{W}_{\mathbf{3 0}}$ acting as an intermediary between exited ZnOEP and spacers.

Interestingly, the direction of the electron transfer depends strongly of the solvent, the photocurrent being anodic in acetonitrile and cathodic in aqueous solution, using the same modified electrodes.

Impedance measurements also indicate that the presence of the $\mathbf{P}_{5} \mathbf{W}_{30}$ improve the electron transfer kinetics between the ITO surface and the film and thus contributes to the enhancement of the photocurrent generation.

Monitoring the thickness of the film is critical for the photocurrent-generation efficiency, probably due to the modification in conductivity of the deposited polymer.

Further developments must address in particular the improvement of the conductivity of the film. In situ measurement of the conductivity will be developed in order to have better understanding about this point. The overall conversion efficiency $\eta$ of the sealed cell need also in the future to be determined. Improving the conductivity of the films will be also important. One possibility to improve the conductivity is the introduction of gold nanoparticles onto the surface. The change of the type of POM (size, charge, redox potential, etc.) will be also scrutinized.

\section{Acknowledgements}

We thank CNRS, the Université de Strasbourg (France), Université Paris-Descartes (Paris, France), Université Pierre et Marie Curie (Paris, France), ICSN, ECE Paris Ecole d'Ingénieurs (France), and Fudan University (Shanghai, China) for funding of this work. LR also thank the Université de Strasbourg for the projet "Idex Attractivité 2012" which has also supported one part of this research, as well as the Oversea Study Program of Guangzhou Elite Project (GEP) for the PhD. grant of Zhaohui Huo. This work was also supported by Fund of senior visiting professor of Fudan University.

CB and ESA wish to thank the "Agence National de la Recherche" (ANR-12-BS07-0014-01) and the ARCANE Labex (ANR-11-LABX-0003-01) for financial support. 


\section{Appendix A. Supplementary data}

Supplementary data associated with this article can be found, in the online version, at http://dx.doi.org/......... 


\title{
Photovoltaic properties of supramolecular assemblies obtained by incorporation of Preysler's type polyoxometalate in a polycationic copolymer of porphyrin
}

\author{
Zhaohui Huo, ${ }^{\text {a }}$ Antoine Bonnefont, ${ }^{a}$ Rana Farha, ${ }^{\text {b,c }}$ Michel Goldmann, ${ }^{\text {b,d }}$ Eric \\ Saint-Aman, ${ }^{\mathrm{e}}$ Hualong $\mathrm{Xu},{ }^{\mathrm{f}}$ Christophe Bucher, ${ }^{\mathrm{g}}$ and Laurent Ruhlmann ${ }^{\mathrm{a} *}$
}

${ }^{a}$ Université de Strasbourg, Institut de Chimie, UMR CNRS 7177, 4 rue Blaise Pascal, CS 90032, 67081 Strasbourg cedex, France, ${ }^{\mathrm{b}}$ Institut des NanoSciences de Paris, UMR CNRS 7588, Université Paris 6, 4 place Jussieu, boîte courrier 840, F - 75252 Paris, France, ${ }^{c}$ Laboratoire d'Analyse et Contrôle des Systèmes Complexes - LACSC-ECE Paris Ecole d'Ingénieurs, 37 Quai de Grenelle, F - 75015 Paris, France, ${ }^{\mathrm{d}}$ Université Paris Descartes, 45 rue des Saints Pères, F - 75006 Paris, France, ${ }^{\mathrm{e}}$ Université Joseph Fourier, Département de Chimie Moléculaire, UMR CNRS 5250, Laboratoire de Chimie Inorganique Rédox, BP-53, 38041 Grenoble Cedex 9, France, ${ }^{\mathrm{f}}$ Department of Chemistry, Shanghai Key Laboratory of Molecular Catalysis and Innovative Materials and Laboratory of Advanced Materials, Fudan University, Shanghai 200433, People's Republic of China. ' Ecole Normale Supérieure de Lyon - Université Lyon 1, Laboratoire de Chimie-UMR CNRS 518246 allée d'Italie 69364 Lyon Cedex 07, France.

Poly-zinc-octaethylporphyrin/ $/ \mathrm{P}_{5} \mathrm{~W}_{30}$ films have been synthesis through incorporation of Preyssler-type polyoxometalate ions, namely $\left[\mathrm{NaP}_{5} \mathrm{~W}_{30} \mathrm{O}_{110}\right]^{14-}\left(\mathbf{P}_{5} \mathbf{W}_{30}\right)$ into zinc octaethylporphyrin/viologen-based polymers (poly-ZnOEP) films. The electrochemical impedance spectroscopy as well as the photovoltaic performances under visible light irradiation have also been investigated.

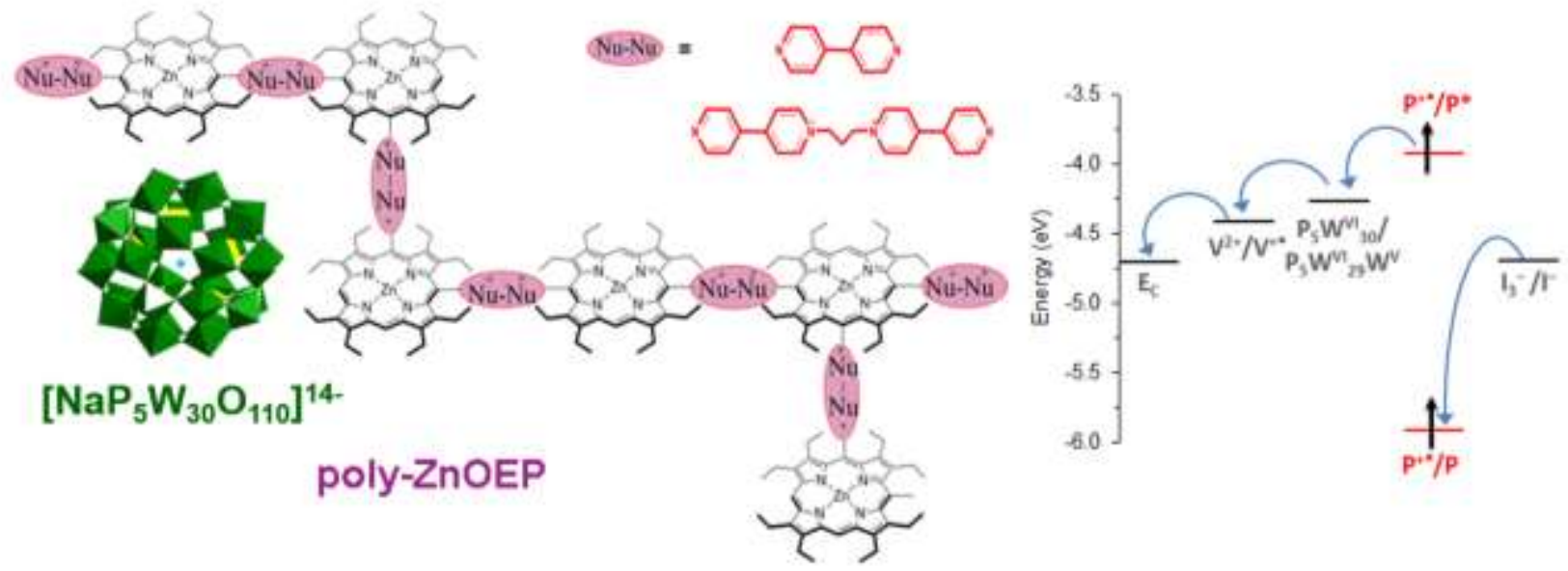




\section{References}

${ }^{1}$ D.-L. Long, R. Tsunashima, L. Cronin, Polyoxometalates: building blocks for functional nanoscale systems, Angew. Chem. Int. Ed. Engl. 49 (2010), 1736-1758.

2 a) M. T. Pope, in Encyclopedia of Inorganic Chemistry, Ed. B. R. King, Wiley, New York, 2005, vol. 7; b)

D.-L. Long, E. Burkholder and L. Cronin, Polyoxometalate clusters, nanostructures and materials: From self assembly to designer materials and devices, Chem. Soc. Rev. 36 (2007) 105-121; c) U. Kortz, A. Müller, J. van Slageren, J. Schnack, N. S. Dalal and M. Dressel, Polyoxometalates: Fascinating structures, unique magnetic properties, Coord. Chem. Rev., 2009, 253, 2315-2327.

${ }^{3}$ M. Jiang, E. Wang, G. Wei, L. Xu, Z. Kang, Z. Li, A novel photochromic multilayer based on preyssler's cluster, New J. Chem. 27 (2003), 1291.

${ }^{4}$ M. Jiang, E. Wang, L. Xu, Z. Kang, S. Lian, The first example of multilayer films with thermochromic properties, J. Solid State Chem. 177 (2004), 1776.

${ }^{5}$ J. Kang, B. Xu, Z. Peng, X. Zhu, Y. Wei and D. R. Powell, Molecular and polymeric hybrids based on covalently linked polyoxometalates and transition-metal complexes, Angew. Chem. Int. Ed. 44 (2005) 69026905.

${ }^{6}$ a) L. Xu, M. Lu, B. Xu, Y. Wei, Z. Peng and D. R. Powell, Towards Main-Chain-Polyoxometalate-Containing Hybrid Polymers: A Highly Efficient Approach to Bifunctionalized Organoimido Derivatives of Hexamolybdates, Angew. Chem. Int. Ed. 2002, 41, 4129 - 4132; Angew. Chem. 2002, 114, 4303 - 4306. b) M. Lu, B. Xie, J. Kang, F. C. Chen, Y. Yang and Z. Peng, Synthesis of Main-Chain Polyoxometalate-Containing Hybrid Polymers and Their Applications in Photovoltaic Cells, Chem. Mater. 2005, 17, 402 - 408. c) S. Chakraborty, A. Keightley, V. Dusevich, Y. Wang, Z. Peng, Synthesis and Optical Properties of a Rod-Coil Diblock Copolymer with Polyoxometalate Clusters Covalently Attached to the Coil Block, Chem. Mater. 2010, 22, $3995-4006$.

${ }^{7}$ a) B. Xu, M. Lu, J. Kang, D. Wang, J. Brown and Z. Peng, Synthesis and Optical Properties of Conjugated Polymers Containing Polyoxometalate Clusters as Side-Chain Pendants, Chem. Mater. 2005, 17 (11), 2841; b) Y. Li, K. Shetye, K. Baral, L. Jin, J.D. Oster, D.-M. Zhub and Z. Peng, Main-chain polyoxometalate-containing donor-acceptor conjugated copolymers: synthesis, characterization, morphological studies and applications in single-component photovoltaic cells, RSC Adv., 2016, 6, 29909-29919.

${ }^{8}$ H. Wu, H.K. Yang and W. Wang, Covalently-linked polyoxometalate-polymer hybrids: optimizing synthesis, appealing structures and prospective applications, New J. Chem., 2016, 40, 886-897.

${ }^{9}$ a) K. J. Elliott, A. Harriman, L. Le Pleux, Y. Pellegrin, E. Blart, C. R. Mayer and F. Odobel, A porphyrinpolyoxometallate bio-inspired mimic for artificial photosynthesis, Phys. Chem. Chem. Phys., 2009, 11, 87678773. b) M. Araghi, V. Mirkhani, M. Moghadam, S. Tangestaninejad and I. Mohammdpoor-Baltork, Synthesis and characterization of a new porphyrin-polyoxometalate hybrid material and investigation of its catalytic activity, Dalton Trans., 41 (2012) 3087-3094. c) M. Araghi, V. Mirkhani, M. Moghadam, S. Tangestaninejad 
and I. Mohammdpoor-Baltork, New porphyrin-polyoxometalate hybrid materials: synthesis, characterization and investigation of catalytic activity in acetylation reactions, Dalton Trans. 41 (2012) 11745-11752. d) C. Allain, D. Schaming, N. Karakostas, M. Erard, J.-P. Gisselbrecht, S. Sorgues, I. Lampre, L. Ruhlmann, B. Hasenknopf, Synthesis, electrochemical and photophysical properties of covalently linked porphyrinpolyoxometalates, Dalton Trans. 42 (2013) 2745-2754.

${ }^{10}$ a) A. Yokoyama, T. Kojima, K. Ohkubo, M. Shiro, S. Fukuzumi, Formation of a Hybrid Compound Composed of a Saddle-Distorted Tin(IV)-Porphyrin and a Keggin-Type Heteropolyoxometalate To Undergo Intramolecular Photoinduced Electron Transfer, J Phys Chem A 115 (2011) 986-997, b) C. Allain, S. Favette, L. Chamoreau, J. Vaissermann, L. Ruhlmann, B. Hasenknopf, Hybrid Organic-Inorganic PorphyrinPolyoxometalate Complexes, Eur J Inorg Chem (2008) 3433-3441, c) A. Falber, B.P. Burton-Pye, I. Radivojevic, L. Todaro, R. Saleh, L. C. Francesconi, C. M. Drain, Ternary Porphyrinato $\mathrm{Hf}^{\mathrm{IV}}$ and $\mathrm{Zr}^{\mathrm{IV}}$ Polyoxometalate Complexes, Eur J Inorg Chem (2009) 2459-2466, d) D. Schaming, C. Costa-Coquelard, I. Lampre, S. Sorgues, M. Erard, X. Liu, J. Liu, L. Sun, J. Canny, R. Thouvenot, L. Ruhlmann, Formation of a new hybrid complex via coordination interaction between 5,10,15-tritolyl-20-(4- and 3-pyridyl)porphyrin or 5,10,15-triphenyl-20-(4-pyridyl)-porphyrin and the $\alpha$-[MSiW $\left.{ }_{11} \mathrm{O}_{39}\right]^{6-}$ Keggin-type polyoxometalate $\left(\mathrm{M}=\mathrm{Co}^{2+}\right.$ and $\mathrm{Ni}^{2+}$ ), D. Schaming, C. Costa-CoquelardInorg Chim Acta 363 (2010) 2185-2192. For an alternative approach and potential use of POM-porphyrin materials, see: (b) D. Hagrman, P. J. Hagrman and J. Zubieta, Solid-State Coordination Chemistry: The Self-Assembly of Microporous Organic-Inorganic Hybrid Frameworks Constructed from Tetrapyridylporphyrin and Bimetallic Oxide Chains or Oxide Clusters, Angew. Chem., Int. Ed., 38 (1999), 3165-3168.

${ }^{11}$ a) I. C. M. S. Santos, S. L. H. Rebelo, M. S. S. Balula, R. R. L. Martins, M. M. M. S. Pereira, M. M. Q. Simões, M. G. P. M. S. Neves, J. a. S. Cavaleiro, A. M. V. Cavaleiro, Association of Keggin-type anions with cationic meso-substituted porphyrins: synthesis, characterization and oxidative catalytic studies, J. Mol. Catal. A: Chem., 2005, 231, 35-45. b) C. Costa-Coquelard, S. Sorgues and L. Ruhlmann, Photocatalysis with Polyoxometalates Associated to Porphyrins under Visible Light: An Application of Charge Transfer in Electrostatic Complexes, J. Phys. Chem. A, 2010, 114, 6394-6400. c) A. Tsuda, E. Hirahara, Y.-S. Kim, H. Tanaka, T. Kawai and T. Aida, A Molybdenum Crown Cluster Forms Discrete Inorganic-Organic Nanocomposites with Metalloporphyrins, Angew. Chem., Int. Ed., 2004, 43, 6327-6331. d) G. Bazzan, W. Smith, L. C. Francesconi and C. M. Drain, Electrostatic Self-Organization of Robust Porphyrin-Polyoxometalate Films, Langmuir, 2008, 24, 3244-3249. e) I. Ahmed, R. Farha, M. Goldmann and L. Ruhlmann, A molecular photovoltaic system based on Dawson type polyoxometalate and porphyrin formed by layer-by-layer self assembly, Chem. Commun., 2013, 49, 496-498.

${ }^{12}$ Z. Huo, D. Zang, S. Yang, R. Farha, M. Goldmann, B. Hasenknopf, H. Xu and L. Ruhlmann, Synthesis and characterization of Lindqvist-type polyoxometalate-porphyrin copolymers, Electrochimica Acta, 2015, 179, 326-335.

${ }^{13}$ J. Hao, A. Giraudeau, Z. Ping, L. Ruhlmann, Supramolecular assemblies obtained by large counteranion incorporation in a well-oriented polycationic copolymer, Langmuir 24 (2008) 1600-1603.

${ }^{14}$ a) R. Kannappan, C. Bucher, E. Saint-Aman, J.-C. Moutet, A. Milet, M. Oltean, et al., Viologen-based redoxswitchable anion-binding receptors, New Journal of Chemistry 34 (2010) 1373. b) A. Iordache, M. Retegan, F. 
Thomas, G. Royal, E. Saint-Aman, C. Bucher, Redox-responsive porphyrin-based molecular tweezers, Chemistry-A European Journal 18 (2012) 7648.

${ }^{15}$ I. Creaser, M.C. Heckel, R.J. Neitz, M.T. Pope, Rigid nonlabile polyoxometalate cryptates $\left[\mathrm{ZP}_{5} \mathrm{~W}_{30} \mathrm{O}_{110}\right](15-$ n) that exhibit unprecedented selectivity for certain lanthanide and other multivalent cations, Inorg. Chem. 32 (1993) 1573-1578.

${ }^{16}$ a) L. Ruhlmann, A. Schulz, A. Giraudeau, C. Messerschmidt and J.-H. Fuhrhop, A Polycationic Zinc-5,15dichlorooctaethylporphyrinate-viologen Wire, J. Am. Chem. Soc., 1999, 121, 6664-6667. b) L. Ruhlmann, J. Hao, Z. Ping and A. Giraudeau, Self-oriented polycationic copolymers obtained from bipyridinium mesosubstituted-octaethylporphyrins, J. Electroanal. Chem., 2008, 621, 22-30.

${ }^{17}$ D. Schaming, I. Ahmed, J. Hao, V. Alain-Rizzo, R. Farha, M. Goldmann, H. Xu, A. Giraudeau, P. Audebert and L. Ruhlmann, Easy methods for the electropolymerization of porphyrins based on the oxidation of the macrocycles, Electrochim. Acta, 26 (2011) 10454-10463.

${ }^{18}$ S. Bruckenstein, M. Shay, Experimental aspects of use of the quartz crystal microbalance in solution, Electrochim. Acta, 30 (1985), 1295-1300.

${ }^{19}$ a) A. Giraudeau, L. Ruhlmann, L. El Kahef, M. Gross, Electrosynthesis and Characterization of Symmetrical and Unsymmetrical Linear Porphyrin Dimers and Their Precursor Monomers, J. Am. Chem. Soc. 1996, 118, 2969-2979; b) M. Kasha, Relation between Exciton Bands and Conduction Bands in Molecular Lamellar Systems, Rev. Mod. Phys. 1959, 31, 162-169; c) J. L. Sessler, M. R. Johnson, S. E. Creager, J. C. Fettinger, J. A. Ibers, Synthesis and characterization of quinone-substituted octaalkyl porphyrin monomers and dimers, J. Am. Chem. Soc. 1990, 112, 9310-9329.

${ }^{20}$ Z. Huo, J.-P. Gisselbrecht, R. Farha, M. Goldmann, E. Saint-Aman, C. Bucher, L. Ruhlmann, Alternating electro-copolymerization of zinc- $\beta$-octaethylporphyrin with a flexible bipyridinium, Electrochimica Acta 122 (2014), 108-117.

${ }^{21}$ D. Schaming, R. Farha, H. Xu, M. Goldmann, L. Ruhlmann, Formation and photocatalytic properties of nanocomposite films containing both a tetracobalt Dawson-derived sandwich polyanion and tetracationic porphyrin, Langmuir, 27 (2011) 132-143.

${ }^{22}$ A. J. Nelson, S. Glenis, A. J. Frank, XPS and UPS investigation of $\mathrm{PF}_{6}$ doped and undoped poly 3-methyl thiophene, J. Chem. Phys. 87, (1987), 5002-5006.

${ }^{23}$ a) Q. Wang, J.E. Moser and M. Grätzel, Electrochemical Impedance Spectroscopic Analysis of DyeSensitized Solar Cells, J. Phys. Chem B, 2005, 109, 14945-14953. b) F. Fabregat-Santiago, J. Bisquert, G. Garcia-Belmonte, G. Boschloo and A. Hagfeldt, Influence of electrolyte in transport and recombination in dyesensitized solar cells studied by impedance spectroscopy, Sol. Energy Mater. Sol. Cells, 2005, 87, 117-131. c) M. Adachi, M. Sakamoto, J. Jiu, Y. Ogata and S. Isoda, Determination of Parameters of Electron Transport in Dye-Sensitized Solar Cells Using Electrochemical Impedance Spectroscopy, J. Phys. Chem. B, 2006, 110, 13872-13880. 